THE EFFECTS OF PRETRAINING CLIENTS TO INCREASE THE IN-COUNSELING FREQUENCY OF AFFECTIVE AND CONCRETE VERBAL BEHAVIOR

DANIEL ERIC SHAW

A DISSERTATION PRESENTED TO THE GRADUATE COUNCIL OF THE UNIVERSITY OF FLORIDA IN PARTIAL FULFILLMENT OF THE REQUIREMENTS FOR THE DEGREE DOCTOR OF PHILOSOPHY UNIVERSITY OF FLORIDA 
To my Mother, Father, and Brother,

whose loving spirit has, and will always be with me.

And especially to Laurie,

for her love, patience, encouragement, understanding, individuality, laughter, and wisdom. 


\section{ACKNOWLEDGEMENTS}

The author wishes to express his sincere appreciation and admiration to the members of his doctoral committee: Dr. Joe Wittmer, for his guidance, structure and genuine facilitative manner, Dr. Max Parker, for his true concern and friendship, Dr. Don Avila, for his honest freedom.

A hearty thank you to the staff, counselors, and trainees of the University of Florida and Bradley University counseling centers, especially Dr. Jim orr and Jo Adams.

A salute and thank you to all the students who participated in and assisted with my research.

An affirmation of loyality to my classroom mentors and heroes:

Dr. Betty siegel, for her warmth and brilliance, Dr. Bill Purkey, "If it's worth doing. . . it's worth doing."

Dr. Art Combs, for Perceptual Psychology. 
TABLE OF CONTENTS

PAGE

ACKNOWLEDGEMENTS. . . . . . . . . . . . . iii

ABSTRACT. . . . . . . . . . . . . . . vii

CHAPTER

I

INTRODUCTION. • • • • . • . • . • • • • • 1

Purpose of the Study. . . . . . . . . . . 4

Definitions of Terms Used . . . . . . . 5

II

REVIEW OF THE RELATED LITERATURE. . . . . . . 7

Pretraining for Counseling. . . . . . . . 7

Counseling as a Learning Process. . . . . . 13

Experiential Learning . . . . . . . . 13

Perceptual psychology Theory of Learning. . 14

Programmed and Self-Instruction . . . . 15

Modeling. . . . . . . . . . . . . 17

Client Verbal Behavior. . . . . . . . 19

Affective Verbal Behavior . . . . . . 20

III PROCEDURES AND METHODOLOGY. . . . . . . . 22

Description of the Population and Sampling

Procedures . . . . . . . . . . . . 22

The Experimental Treatments . . . . . . 24

Counselors and Data Collection. . . . . . 25

Scoring and Dependent Measures. . . . . . 25

Research Design and Hypothesis. . . . . . 26

Basic Design. . . . . . . . . . 26

Analysis of the Data. . . . . . . 27

Hypotheses. . . . . . . . . . 27

IV RESULTS . . . . . . . . . . . . 29

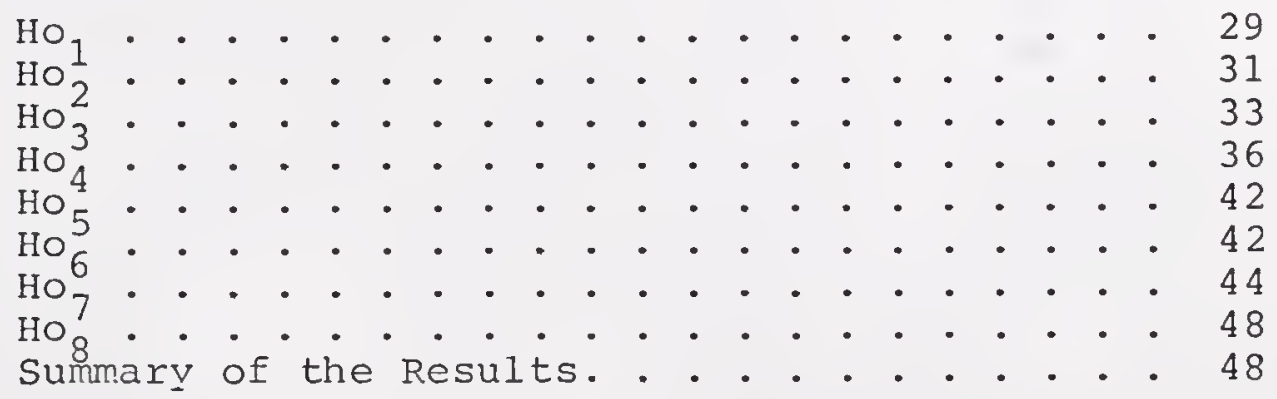


DISCUSSION AND IMPLICATIONS • • • • • • • • 52

Summary of the Findings . . . . . . . . 53

Discussion. . • • • • . • . • • • . • . 54

Implications. . . . . . . . . . . . . 55

Recommendations for Future Research . . . . 56

Limitations . . . . . . . . . . . . 58

APPENDICIES

A INFORMED CONSENT FORM - . . . . . • • • • • • 59

B CONTROL GROUP INFORMATION . . . . . . . . . . 61

C TAPESCRIPT OF AUDIO-TAPE $\left(\mathrm{SIM}_{2}\right) \cdot$ • • • • • • • 62

D PROGRAMMED INSTRUCTION WORKBOOK $\left(\right.$ SIM $\left._{3}\right) \cdot \cdots \cdot$ • 72

E SUPPLEMENTAL INSTRUCTIONS • • • • • • • • • • . 84

F SUPPLEMENTAL INSTRUCTIONS • • • • • • • • • . . 85

REFERENCES • • • . . . . . . . . . . . . . . . . . . 86

BIOGRAPHICAL SKETCH. • • • • • • • • • • • • • • • • 92 
Abstract of Dissertation Presented to the Graduate Council of the University of Florida in Partial Fulfillment of the Requirements for the Degree of Doctor of Philosophy

\title{
THE EFFECTS OF PRETRAINING CLIENTS TO INCREASE THE IN-COUNSELING FREQUENCY OF AFFECTIVE AND CONCRETE VERBAL BEHAVIOR
}

\author{
By \\ DANIEL ERIC SHAW \\ June, 1981
}

Chairman: P. Joseph Wittmer

Major Department: Counselor Education

Individuals who seek help through personal counseling experience varying time intervals after requesting counseling and before they actually meet face to face with a counselor. This study addressed procedures counselors could use during this lapsed time period which would better prepare their clients for later counseling. Specifically, the purpose of this investigation was to study the effects of three different self-instruction modules on clients prior to counseling. The aim of the modules was to prepare individuals for counseling during the interval prior to actual counseling by teaching them two communication skills which would be beneficial to them in later counseling. These skills were: (1) affective verbal expression and (2) the concrete verbalization of these expressions. Affective verbal expression was defined as the 
total count of affective words or phrases emitted by a client during a 15-minute audio-taped analyzed segment of his/her first counseling session. Concreteness was operationally defined as an increase in the frequency of specific selfreferent affective statements and a concomitant decrease in the frequency of the client's specific and nonspecific other referent affective statements during counseling. Specifically, this study examined the effects of self-instruction via: a written programmed instruction workbook, (2) modeling via an audio-taped simulated counseling session, and (3) the combination of these two techniques. A total of 52 subjects seeking personal counseling took part in this study and were randomly assigned to three experimental groups and one control group.

Eight hypotheses were tested in order to locate significant differences between the three experimental groups and the one control group on the dependent measures. Using analysis of variance and post-hoc Duncan's Multiple Range Test, two of the eight hypotheses were rejected at the alpha level of $\underline{p}<$ .05 and one at the $\underline{p}<.005$ level of significance. Basically, the results indicated that the module using modeling alone and the module combining the techniques of programmed instruction and modeling were effective pretraining techniques for increasing the frequency of affective verbal expression emitted by clients in a later counseling session. Also, modeling via an audio-taped simulated counseling session was shown to significantly increase the frequency of specific self-referent 
affective statements. The dependent measures of specific and nonspecific other referent affective statements were not significantly effected by the self-instruction modules. In summary, two of the three self-instruction modules proved to be effective in preparing clients prior to counseling. 
CHAPTER I

INTRODUCTION

In the classic $1940^{\prime} \mathrm{s}$ motion picture, "The wizard of Oz," the protagonist Dorothy, found herself in a very strange place following an extremely traumatic event in her life. She was troubled and asked those around her what she should do in order to resolve her problem. She was advised to go to the Emerald City and speak with some kind of wizard or something like that. You see, maybe the wiz could help her with her problem. When she asked how she might find the Emerald City where the Wizard lived and worked, she was told to follow the road that was paved with yellow brick. They, the Munchkins, told her to begin at the beginning.

Dorothy began her long journey alone and discovered many things about herself along the way before seeing the wizard. Unfortunately, after speaking to the Wizard at the Emerald City she realized that he was unable to help her. Dorothy was finally helped through the facilitation of a very warm, genuine, and empathic witch who assisted her in discovering the power she herself possessed. (Shaw, 1980)

Like Dorothy, many individuals find themselves lost and troubled. Some of these individuals turn to counseling and become clients. Unlike many clients, Dorothy had some positive assistance with her problem by being prepared by another prior to seeing the wizard, on what she might do to facilitate her audience with him. Can we as counselors positively assist clients prior to counseling so that they might be "better" clients? This question is the focus of this study. 
Many investigators have researched the technique of preparing clients for counseling. That is, exposing the client(s) to, or involving the client(s) in some form of learning experience prior to the actual counseling interaction that will hopefully be of significant therapeutic value during the process of counseling. Basically, these investigations have approached this preparation for counseling from one of two angles: (1) an information process that operates on the set of expectations that clients bring to counseling or (2) teaching the client predesignated appropriate behaviors to engage in and exhibit during counseling as predetermined by the individual investigator or investigative team.

Similar techniques have been utilized with varying results to operate on client expectations and/or behaviors. According to Sauber (1974), there are basically three approaches to the pretraining/preparation technique: role induction, vicarious precounseling training based on imitation/modeling procedures, and therapeutic reading (bibliotherapy). The approach dealing with client expectations attempts to bring the clients' expectations of counseling to a level which approximates the actual experience of counseling. Both Goldstein (1976), with individual clients, and Cartwright (1972), with group clients, utilized an audiovisual preparatory film that informed, explained and illustrated through modeling the process of counseling. This method assumes that the client who understands the process 
of counseling will benefit more from the counseling than those who do not (Holmes \& Urie, 1975; Urie, 1974).

The approach of teaching clients specific or appropriate behaviors can be subdivided into two different modes of learning: modeling and direct instructions. This approach attempts to teach clients various behaviors thought to be beneficial to the counseling process, that is, self-disclosure, accurate expression of feeling, statements of positive self-reference, present tense verbalizations, and statements that indicate self-exploration. Exposure to films, audiotapes or video-tapes, written and verbal descriptions, and written and verbal instructions are the instructional mediums that have been used to transmit the information to the client. Learning via modeling and direct instructions seems to be the major thrust of the pretraining/preparation research (DelBeato, 1971; Galdaleto, 1976; Green \& Marlatt, 1972; Hemmerich, 1976; Long, 1968; Myrick, 1968, 1969; Navabinejad, 1977) .

Role induction, which has been used in and during the therapeutic relationship attempts to orient the client to the process of counseling. This is achieved by informing the client through a didactic interaction with a counselor as to the process of counseling, expected behaviors, psychological and behavioral dynamics, and other issues relevant to counseling (Hoehn-Saric, Frank, Imber, Nash, Stone, \& Battle, 1964; Sauber, 1974). 
The results of the above studies indicate both successful and unsuccessful outcomes as a result of pretraining. This study focused on a uniquely different approach to pretraining clients for counseling. This study is predicated on the assumption that it is highly important and necessary that clients be aware of, be able to express and understand their feelings as well as be able to communicate their thoughts and feelings in a clear and unambiguous manner during counseling (Buscaglia, 1972; Greenwald, 1973; Hayakawa, 1979) .

\section{Purpose of the Study}

The purpose of this study was to design, develop, and measure the effects among and between three self-instruction modules designed to teach preclients two communication skills for positive growth within the counseling relationship: (1) affective verbal expression of felt emotion and (2) the concreteness of their verbally expressed affect. More specifically, this study attempts to answer the following questions: (1) Is a written, programmed instruction workbook approach to a self-instruction module effective in increasing the dependent measures of affective verbal expression and concreteness? (2) Is an audio-taped client model approach to a self-instruction module effective in increasing the above mentioned dependent measures?

(3) Are the combined approaches to the self-instruction modules (both written programmed instruction workbook and audiotaped client model) together as one, effective in increasing 
the above mentioned dependent measures? And, (4) which of the modules or combination of the two prove to be more effective in increasing the dependent measures emitted by clients in a later counseling session?

\section{Definition of Terms}

For the purpose of this study, the following definitions apply.

Self-instruction module $\left(\right.$ SIM $\left._{1}\right)--a$ self-contained, and self-applied programmed instruction package. The SIM $_{1}$ in this study used an audio-taped client model and a written programmed instruction workbook to assist the preclient user in reaching the desired criteria. (Appendix $C$ and D)

$\mathrm{SIM}_{2}$--the audio-taped client model component of the SIM $_{1}$ used independently as a separate treatment. (Appendix C)

$\mathrm{SIM}_{3}$--the written programmed instruction workbook component of the $\mathrm{SIM}_{1}$ used independently as a separate treatment. (Appendix D)

Affective verbal expression (AVE)--words or phrases emitted by the client that he/she uses to describe feelings. AVE was measured by counting each occurrence of affective words or phrases emitted by the client.

Concreteness--that dimension of human language which characterizes the specificness and explicitness 
of the communication. Concreteness has been described as the polar opposite of vagueness. For the purpose of the study, concreteness is operationally defined as an increase in specific self-referent affective statements and a decrease in specific and nonspecific other referent affective statements.

Specific self-referent affect (SSRA)--affective words or phrases used in a self-referent manner. The presence of first person pronouns used in conjunction with affective words or statements. (Example: "I'm confused." or "That's confusing for me.")

Specific other referent affect (SORA)--affective words or phrases used in an other referent manner. The presence of second person pronouns used in conjunction with affective words or phrases or affective words or phrases used to describe the emotion of specifically identified other individviduals by name. (Example: "She's unhappy." or "Bill is angry at me.").

Nonspecific other referent affect (NORA)--affective words or phrases that are attributed to either self or other individuals without the use of a first or second person pronoun or name of a specifically identified other individual. (Example: "That's upsetting." or "It's terrible."). 
CHAPTER III

REVIEW OF THE RELATED LITERATURE

Three self-instruction modules designed to increase the frequency of affective and concrete verbal behavior in clients were the focus of this study. This topic includes many theoretical considerations concerning the scope, nature, and aim of counseling. More specifically, this study dealt with the training of clients prior to counseling and examined the effects of programmed instruction and modeling on the affective and concrete verbal behavior of clients during their initial counseling session and investigated the differing impact of the three modules.

\section{Pretraining for Counseling}

Myrick (1969) stated that Truax was one of the first to report the potentialities of modeling and imitative learning in counseling. Truax called his technique vicarious therapy pretraining (VTP). VTP utilized an audio-tape of clients exploring their feelings. This audio-tape served as a model during pretraining with those clients scheduled for counseling. The subjects in the study were told, prior to hearing the tape, that this was an example of good client behavior. Exposure to a model prior to receiving counseling was an intergral dimension of the 
study, though not controlled for as an experimental variable. Myrick (1968) was interested in the use of modeling as a means of orienting high school students to counseling. He found that an audio-taped model was significantly more effective than a video-taped model in increasing the frequency of the subjects' use of first person proriouns during the initial counseling interview.

One of the major points of Myrick's study was the orientation to counseling. This orientation was intended as a means of preparing the high school student for counseling, with specific attention to their verbal behavior during the counseling session which followed the orientation. Citing the learning process in the classroom Myrick stated that "consequently, it seems reasonable to concentrate on orienting clients to both the stimulus and response aspects of counseling" (p. 1.).

Another form of client preparation for counseling, The Role Induction Interview (RII), was empirically tested by Hoehn-Saric et al. (1964). Outpatient psychiatric clinic patients were involved in a group process (RII) in which an informal discussion took place concerning the patients' expectations about the upcoming psychotherapeutic process. The RII is an instructional and didactic process that explains the nature of psychotherapy, expected patient behavior, expected patient dynamics, and realistic expectations for improvements. The RII is basically concerned with the expectations that clients and patients bring with them 
to therapy/counseling. It is widely believed that client/ patient expectations play an important part in the process and outcome of counseling/therapy. Research indicates that client/patient expectations about the entire counseling/ therapy process vary and that these expectations seem to influence the counseling process and outcome. There is an indication that the length of counseling tends to decrease the amount of anticipation a client has concerning his/her expectations of an expert or accepting counselor (Gelso, Brooks, \& Karl, 1975; Goldstein, 1962; Scaccuzzo, 1975; Tinsley, 1976; Ziemelis, 1974). Results of the Hoehn-Saric et al. (1964) study showed favorable outcomes on patient expectations following participation in the Role Induction Interview. It is important to note that the RII is not intended to be a psychotherapy session since it is used prior to entering therapy/counseling and, as such, is a pretraining technique.

Concerning Myrick's statement on high school student orientation to counseling, Sauber (1974) appeared to be in agreement when he stated that "if certain patient behaviors are necessary for successful therapy, why not increase the probability of their occurrence by arranging pretherapy training experiences?" (p. 190).

Sauber (1974) sought to investigate the effects of the major approaches to pretraining on the various processes and outcomes of counseling/psychotherapy. He found that counseling/therapy which employed pretraining techniques generally led to successful outcomes. 
A through review of the recent literature reveals an upsurge of interest in the use of pretraining for counseling techniques. Numerous studies have demonstrated, with varying results, the relative effectiveness of utilizing various modes of pretraining for counseling techniques.

Wuehler (1976) evaluated the effectiveness of videotaped modeling and the precounseling counselor/client interview on the dependent measure of client self-disclosure and counseling expectations. Three groups of subjects were utilized: those who viewed the video-taped model, those who viewed the video-taped model and then discussed it with a counselor, and a control group, consisting of those who received no treatment. No differences were found between the experimental groups, but the findings indicated that the video-taped model was effective in eliciting self-disclosure behaviors and reducing incongruent expectations.

Isenberg (1975) examined the relationship between client personality dimensions and counselor style in the preparation process. It was found that the counseling sessions were considered more beneficial to the client when his/her expectations closely resembled the actual experience of the counseling session.

Slaney (1974) hypothesized that the presentation prior to receiving counseling of audio-taped information describing desired client behavior would increase the frequency of the desired behavior's occurrence. Seven different 
treatments were used to manipulate client expression of the problem, self-exploration, and frequency of self-referent affective statements. No statistically significant results were found to support the treatments used. Richardson (1977) utilized a 30-minute video-tape that presented a model and information about counseling to increase the client's knowledge of the counseling process, reduce anxiety, and modify client counseling attitudes. Results indicated that the client's knowledge of counseling was significantly infulenced by the pretraining with a video-tape experience, although no support could be found for its effect on the client's anxiety and attitudes about counseling. Overall, the pretraining experience was thought to be an appropriate intervention technique.

Shannon (1975) investigated the effects of three specific precounseling techniques for continuation in counseling: (1) a brief written statement, (2) a video-taped explanation, and (3) an interview with a counselor. Results showed that those subjects who saw the video-tape and those who had the brief interview with a counselor had a significant increase in the continuation in counseling. Those who read the brief written statement (and the control subjects) did not significantly increase their continuation in counseling.

Martin (1975) investigated the effects of a counseling orientation audio-tape on the dependent measures of (1) counselor rating of client problem expression, (2) client 
personality dimensions, and (3) mode of counseling termination. Results fully supported the precounseling treatment on all three dependent measures.

Fernbach (1975) studied the effect of a written document on client expectations and specific appropriate client behaviors such as termination, attendancè, and rating of the therapy experience. Orenstein (1974) demonstrated the effects of pretherapy client role preparation techniques on both client and therapist attitudes and expectations concerning the upcoming counseling sessions. Reeves (1978), although finding no significant results, assumed that precounseling information transmission was an appropriate precounseling intervention.

The bulk of the above mentioned research indicates that the most effective precounseling training techniques employed modeling via a media approach, or some form of direct instructions for the acquisition of specific behaviorally identifiable, predesignated, appropriate client behaviors, which included affective verbal expression and self-referent affective statements. The decision to use a precounseling technique was arrived at through a logical examination of the nature of the possible applications of the various modes of precounseling techniques and empirical research considerations. Future research on precounseling techniques might benefit from an examination of the temporal dimension of the precounseling technique. 
Counseling as a Learning Process

Why does an individual seek counseling? The answer is, presumably, to make some sort of positive change in a certain area (or areas) of his/her existence which he/she has been unable to accomplish by his/herself. The client seeks the help, expertise, and knowledge of a trained prof̀essional.

- Learning involves the changes in behavior that an organism makes in order to adapt to its physical and social environments. A change in behavior as a result of experience (in this case, counseling) is what is commonly accepted as learning (Mikulas, 1974, 1978; VanDerveer, 1974). In this sense, counseling is basically an event that provides the opportunity for the client to make perceptual, attitudinal, behavioral, emotional, and cognitive changes (VanDerveer, $1974)$.

\section{Experiential Learning}

Rogers (1969) believes that learning is divided into two general types. He implies a mode of instruction by describing a continuum in which one end is material rich in personal meaning for the individual and the other end is material which has little personal significance. He cites the example of learning nonsense syllables, which are not easy to learn and are likely to be forgotten, because there is little, if any, personal meaning involved. At the other extreme lies experiential learning, which is high in personal meaning. Rogers defined experiential learning as follows: 
"It has a quality of personal involvement, the whole person in both his feeling and cognitive aspects being in the learning event. It is self-initiated. Even when the impetus or stimulus comes from the outside, the sense of discovery, of reaching out, of grasping and comprehending comes from within. It is pervasive. It makes a difference in the behavior, the attitudes, perhaps even the personality of the learner. It is evaluated by the learner. He knows whether it is meeting his need, whether it leads toward what he wants to know, whether it illuminates the dark area of ignorance he is experiencing. The locus of evaluation we might say, resides definitely in the learner. Its essence is meaning. When such learning takes place, the element of meaning to the learner is built into the whole experience." (p. 5).

Perceptual Psychology Theory of Learning

Combs and Snygg (1959) and Combs, Richards, and Richards (1976) offered a definition of learning similar to that of Rogers; that is, learning is an active process such as experiencing, and behavior that results from an individual's effort to safisfy personal needs. Learning is a differentiation of personal meaning. The relationship of the individual's needs to any given moment determines what the person learns, or differentiates, in a given situation. The greater the relationship of the material to be learned to the learner, the higher the probability that the learner will attend to and be successful in learning the material. The 
more personal meaning is involved, the greater are the chances that the individual will actively attend to the material (Combs \& Snygg, 1959; Combs et al.; 1976; Purkey 1970; Rogers, 1951). Combs (1954) stated that counseling is a learning process; successful counseling occurs when the client learns a new and better relationship between him/ herself and the world in which he/she lives. The goal of counseling is to aid the client in achieving a perceptual field as rich, varied, accurate, and free of distortion as possible.

It appears that a self-instruction module that focuses upon the individual client's own affective verbal behavior adequately fits both the experiential and perceptual psychological views of learning, because the client him/herself is allowed to use his/her own words which fit his/her unique personal experience.

Programmed and Self-Instruction

According to Mikulus (1974), the area of programmed instruction was originally investigated by $\mathrm{S}$. C. Pressy in the 1920's but was carried on by B. F. Skinner and his colleagues. Programmed instruction is based on the principles of behavioral reinforcement, knowledge of results, and learning theory. Learning via this process is a highly systematized, dynamic, and structured event in which specific goals are identified by terminal behaviors. The material to be learned is identified in advance and is presented in a series of logical units. Through the process of shaping, 
the learner is at first given small amounts of the material to be learned and is then requested to respond to the material with increasing magnitude (Mikulus, 1972, 1974, 1978; Maurer, 1976; Reynolds, 1968; Skinner, 1953, 1968). Mikulus (1974) states that programmed instruction has several desirable elements; it involves active student participation, immediate feedback, and self-pacing. Mikulus recognizes that some individuals find programmed instruction too constricting, preferring, conceptualized, more flexible, integrative learning experiences.

Kirk (1977) investigated the effects of a self-instruction program in increasing clients' readiness for counseling and psychotherapy. A sample of students at Florida state University was divided into two groups: one group received what he termed the Counseling Readiness Program and the other group served as the control. Results indicated insignificant increases on the Gough Adjective Check List, of the Counseling Readiness Scale. However, it was found that the subjects' expectations corresponded more closely to the expectations that counselors hold concerning the counseling process.

Maurer (1976) investigated the effects of a selfinstruction program on facilitation and communication skills for elementary school teachers. The experimental group subjects of elementary school teachers received a 15 lesson self-instruction module, designed to increase the frequency of facilitative teacher responses. Results were significant 
at the $\underline{\mathrm{L}} \leq .05$ level for the dependent measures of facilitative teacher verbal response pattern, teacher written response identification, and student perception of teacher verbally expressed affect.

Higgens, Ivey, and Uhlemann (1970) investigated the use of what they termed media therapy, in a programmed instruction approach, for teaching clients in dyads the verbal skills of direct mutual communication. Three treatment groups were used: (1) full treatment (media therapy), programmed text and video models only, and (3) reading material only. Results indicated that the full treatment (media therapy) was the most successful of the three in improving the frequency of direct mutual communication.

The preceding literature and research support the use of a programmed instruction approach for teaching specific client verbal behaviors.

\section{Modeling}

Thus far, several theoretical positions on learning have been discussed. One of the most frequently studied and researched is social learning theory. Modeling, imitation, or observational learning (as it is sometimes called) comprises a large portion of the literature in social learning theory. According to social learning theory, modeling is the process whereby human behavior is learned by observing others. The theory states that most human behavior is learned observationally, which might account for the high probability of success in research that uses modeling to 
teach certain behaviors. It is believed that the individual forms an ideal of how new behaviors are performed, and later this idea serves as a guide for replication of that behavior. Current research shows a wide scope of human behaviors that are learned via modeling, including specific client verbal behaviors in counseling (Bandura, 1971, 1972, 1977; Dankowski, 1976; Green \& Marlatt, 1972; Hemmerich, 1976; Hosford, 1980; Krumboltz, 1980; Myrick, 1968, 1969; Raque, 1974; Scheiderer, 1977; Schmitz, 1974; Shery, 1976; Thorenson, Hosford, \& Krumboltz, 1970; Whalen, 1969; Wuehler, 1976).

Hemmerich (1976) utilized a video-taped pretraining therapy film with clients who were unfamiliar with the counseling process. The clients were exposed to the videotaped pretraining therapy film which combined both didactic and modeling techniques to encourage the accurate expression of feelings during the initial counseling session. Results testified to the powerful influence of modeling and didactic instructions on the in-counseling behavior of pretrained clients.

Green and Marlatt (1972) compared the effects of instruction and modeling on affective verbalizations and descriptive verbalizations made by clients during a counseling session. Results from this study provided clear evidence that modeling as well as instructions (independently and combined) were instrumental in increasing the frequency of the dependent measures. 
Scheiderer (1977) showed how modeling was successful in producing self-disclosure behaviors with clients, as measured during the initial counseling interview. Dankowski (1976) also found that preinitial counseling training with an audio-taped model was successful in producing selfdisclosure behaviors.

Whalen (196), convinced of the effectiveness of modeling, tested its influence on group verbal behaviors. One hundred twenty-eight male volunteers taken from an introductory psychology class were assigned to one of four groups. The groups were either exposed to a film model high in interpersonal openness (which included descriptive instructions), a film model with minimal instructions, detatiled instructions and no film model, or a minimalinstructions-only treatment. The group exposed to the film model high in interpersonal openness and detailed instructions tended to engage in interpersonal openness while the other groups failed to demonstrate the desired behaviors during a subsequent group counseling experience.

Citing Bandura, DelBeato (1972) indicated that the mere presentation of a model does not insure that the observer will attend to the model. DelBeato suggested that a refinement of the modeling technique is needed.

Client Verbal Behavior

According to Truax, as reported by Myrick (1968), descriptions of the counseling psychotherapeutic process 
are concerned with clients' self-disclosure and selfexploration. Obviously, this process involves clients engaging in extensive verbal behaviors which communicate to themselves, as well as the counselor, their basic personal experiences as they relate to counseling. The role of the counselor is to facilitate the clients' verbal behaviors. Myrick therefore concluded that "verbal behavior, . . particularly in client-centered counseling, is an indispensible part of the counseling process" (p. 21).

Whalen (1969) stated that the goal of psychotherapy often includes the manipulation of a variety of complex client verbal behaviors, especially affective statements. Because verbal behavior is the primary manner in which the client communicates his/her internal experience, FrommReichman (1950) stated that listening to what the client has to say is the basic psychotherapeutic instrumentality. obviously, what the client says during counseling/psychotherapy is highly important and is related to the success of the counseling process.

Krumboltz (1966) advocated the use of specific behavioral goals, of which affective verbal behavior is a part.

\section{Affective Verbal Behavior}

Greenwald (1973) contended that one of the more important values that he holds as a psychotherapist is the importance of the fact that individuals, especially clients, be aware of, and express, their feelings. Current training 
of counselors and therapists emphasizes the importance of the facilitator communicating his/her understanding of the client's internal experience and expressed feelings (Carkhuff, 1969, 1971, 1972; Combs et al., 1978; Egan, 1975; Rogers, 1951; Standish, 1971; Wittmer \& Myrick, 1974). There has been meaningful research on the therapeutic relationship concerned with the manipulation of affective verbal behaviors (Lukens, 1969; Merbaum \& Lukens, 1968; Scheiderer, 1977). Of particular importance to this study was the work of Lukens (1970), who investigated several intervention techniques designed to increase the frequency of clients emitting positive affective verbalizations. The study confirmed that direct instructions would have a more immediate and sustaining effect on client positive affective verbalizations than would counselor reflection of feelings. In addition, Green and Marlatt (1972), as mentioned before in the discussion on modeling, showed that the frequency of affective verbalizations could be increased through modeling and direct instructions 


\section{PROCEDURES AND METHODOLOGY}

Many graduate programs in counselor preparation teach their students a counseling model which emphasizes among other communication dimensions, the reflection of feeling and concreteness of the reflected communication. This client centered model is often utilized in the relationship building phase of the therapeutic relationship. It appears evident then, to assume that it would be advantageous for potential clients, prior to receiving counseling, to have an understanding of and a beginning functional skill in these communication dimensions. This was the focus of this study. More specifically, it was the purpose of this study to design and measure the effects of three different selfinstruction modules and their major components. These self-instruction modules were developed for the purpose of teaching clients prior to counseling two communication skills necessary for growth within the counseling relationship: (1) affective verbal expression and, (2) concreteness of the verbally expressed affect.

\section{Description of the Population and Sampling procedures}

The target population for this study were University of Florida and Bradley University students who came to their 
respective psychological and vocational counseling centers for either personal or vocational counseling. Clients in crisis were not requested to volunteer for this study. These clients were considered inappropriate as the highly emotional concerns are not considered suitable for the selfinstruction modules developed for this study and, of course, ethically could not be assigned to the control group.

Clients who walked in to the counseling centers requesting personal or vocational counseling and who fit the basic guidelines as mentioned above were given a short typed statement by the receptionist at the front desk. This statement (Appendix A) briefly described the study, requested their participation, and emphasized the confidentiality of the study. Those who agreed to participate were randomly given by the receptionist either self-instruction module ${ }_{1}$ ' self-instruction module ${ }_{2}$, self-instruction module ${ }_{3}$, or received another brief typed statement (Appendix B) which explained that they were to be part of the control group and had the option to complete a self-instruction module after the data were collected (directly following the initial counseling session). A total of 52 subjects volunteered for this study.

Upon receipt of the self-instruction module ${ }_{1}$, selfinstruction module ${ }^{\prime}$, or self-instruction module ${ }_{3}$, the experimental subjects and the control subjects were scheduled an appointment with a counselor. The experimental subjects were instructed to complete the module they had received 
before reporting for their scheduled counseling appointment.

\section{The Experimental Treatments}

Self-instruction module ${ }_{1}\left(\right.$ SIM $\left._{1}\right)$ consisted of two basic information transmission and learning mediums. The first was an audio-taped client model on a standard cassette tape which provided the individual user with an understanding via modeling and instruction of what a good example of high affective verbal expression and concrete client communication is. The second medium was a written programmed instruction workbook which assisted the individual user to identify his/her own baseline of affective verbal expression and concreteness. Through a series of written programmed instruction exercises, the individual was taught to increase the frequency of his/her affective verbal expression and concrete client communication. This workbook also contained for reference an affective vocabulary list (Gazda, Asbury, Blazer, Childers, \& Walters, 1977).

The goal of the $\mathrm{SIM}_{1}$ as well as $\mathrm{SIM}_{2}$ and $\mathrm{SIM}_{3}$ was to increase the individuals frequency of verbally expressed affective words or phrases, and the frequency of concrete affective statements with a counselor during forthcoming counseling sessions. SIM $_{1}$ also included two brief typed pages of supplemental instructions (Appendix $\mathrm{E}$ and $\mathrm{F}$ ).

$\mathrm{SIM}_{2}$ was the same audio-taped client model used in SIM $_{1}$ (Appendix C). This audio-taped client model was used as a separate treatment as $\mathrm{SIM}_{2} \cdot \mathrm{SIM}_{2}$ also included a brief typed page of supplemental instructions (Appendix E). 
$\mathrm{SIM}_{3}$ was the same written programmed instruction workbook as used in SIM $_{1}$ (Appendix D). This written programmed instruction workbook was used as a separate treatment as $\mathrm{SIM}_{3} \cdot \mathrm{SIM}_{3}$ also included a brief typed page of supplemental instructions (Appendix E).

In summary, there were four groups. Experimental group one, which received SIM $_{1}$. Experimental group two, which received $\mathrm{SIM}_{2}$. Experimental group three, which received $\operatorname{SIM}_{3}$. And the fourth group comprised the control group who did not receive a self-instruction module.

\section{Counselors and Data Collection}

The counselors in this study were the regular intake counselors from the psychological and vocational counseling centers at the University of Florida and Bradley University. They were not informed of the detailed purpose of the study in order to control for counselor biasing and were requested to treat the client in the normal fashion during counseling.

The counselors were instructed to audio-tape the initial counseling session following the administration of the experimental treatment. This audio-tape provided an objective record from which the data were scored and analyzed.

\section{Scoring and Dependent Measures}

To achieve a representative sample of the audio-taped counseling session, five minute segments were selected from the beginning, middle, and end of each tape. This provided a total of 15 minutes for each audio-tape. Scores were 
obtained on the dependent measures by two trained raters from the University of Florida graduate psychology program who had previous experience in rating and scoring audio-taped counseling sessions.

The dependent measure of verbally expressed affect (AVE) was scored by counting each occurrence of affective words or phrases emitted by the client. The dependent measure of specific self-referent affect (SSRA) was scored by counting each occurrence of first person pronouns emitted in conjunction with affective words or phrases. The dependent measure of specific other referent affect (SORA) was scored by counting each occurrence of second person pronouns or specifically identified others by name emitted in conjunction with affective words or phrases. The dependent measure of nonspecific other referent affect (NORA) was scored by counting each occurrence of affective words or phrases that were not emitted in conjunction with a first or second person pronoun or name of a specifically identified other individual.

\section{Research Design and Hypothesis}

\section{Basic Design}

The research design used in this study was the Post Test Only Randomized Control-Group Design as described by Campbell and Stanley (Issac \& Michael, 1971, p. 42).

The experimental design consisted of four groups, three experimental groups and one control group. 
Analysis of the Data

The data collected in this study were analyzed by using a one-way analysis of variance in conjunction with a posthoc Duncan's Multiple Range Test. Interrater reliability was tested using Pearson's Product-Moment correlation coefficient method. An advance decision was made to accept a correlation of .75 or above. The interrater reliability coefficient for the raters in this study was .82. All hypotheses were tested for a $\underline{p} \leq .05$ level of significance.

\section{Hypotheses}

$\mathrm{Ho}_{1}$ : There is no statistically significant difference between the experimental and control groups on the dependent measure of affective verbal expression $(\mathrm{AVE})$.

$\mathrm{Ho}_{2}:$ There is no statistically significant difference between experimental group one as compared with groups two and three on the dependent measure of AVE.

$\mathrm{Ho}_{3}:$ There is no statistically significant difference between the experimental and control groups on the dependent measure of specific self-referent affect (SSRA) .

$\mathrm{Ho}_{4}:$ There is no statistically significant difference between experimental group one as compared with groups two and three on the dependent measure of SSRA. 
$\mathrm{HO}_{5}$ : There is no statistically significant difference between the experimental and control groups on the dependent measure of specific other referent affect (SORA) .

$\mathrm{Ho}_{6}$ : There is no statistically significant difference between experimental group one as compared with groups two and three on the dependent measure of SORA.

$\mathrm{Ho}_{7}$ : There is no statistically significant difference between the experimental and control groups on the dependent measure of nonspecific other referent affect (NORA) .

$\mathrm{Ho}_{8}:$ There is no statistically significant difference between experimental group one as compared with groups two and three on the dependent measure of NORA. 
CHAPTER IV

\section{RESULTS}

The purpose of this study was to develop and investigate the effects of three different self-instruction modules on preclients (clients waiting for their first counseling session) frequency of affective verbal expression and concreteness of their verbally expressed affect during a later counseling session. This chapter gives the results of the data analysis relative to the four dependent variables, affective verbal expression (AVE), specific selfreferent affect (SSRA), specific other referent affect (SORA), and nonspecific other referent affect (NORA). The results are presented in the order in which they were initially discussed and outlined in chapter III.

$$
\underline{\mathrm{HO}}_{1}
$$

In general, null hypothesis \#1 stated that no significant differences would exist between the experimental groups of preclients receiving the self-instruction modules and the control group on the dependent measure of affective verbal expression (AVE) during a later counseling session.

The results of the one-way analysis of variance, presented in Table 1 , indicate that a significant difference was found between the groups on the measure of affective 
TABLE 1

ANALYSIS OF VARIANCE

USING AVE SCORES

\begin{tabular}{lrrrr}
\hline Source of Variation & DF & SS & MS & F \\
\hline Group & 3 & 205.36 & 68.45 & 5.04 \\
error & 48 & 652.11 & 13.58 & \\
Total & 51 & 857.48 & & \\
\hline
\end{tabular}

$\star p<.005$ 
verbal expression (AVE) with an $F$ of 5.04 and $\underline{p}<.005$. Therefore null hypothesis \#I was rejected. Analysis of variance only indicates whether a significant difference has occurred or not. In this study three separate treatments were employed. Post-hoc analysis on the dependent measure of affective verbal expression (AVE) was performed in order to indicated where the significant difference(s) occurred between the three experimental groups and the control group. This was tested as stated in null hypothesis \#2.

$$
\underline{\mathrm{HO}}_{2}
$$

There is no statistically significant difference between experimental group one as compared with groups two and three on the dependent measure of AVE .

The attempt here was to discover which of the two major parts of $\mathrm{SIM}_{1}$, that being a combination of an audio-taped simulated counseling session $\left(\mathrm{SIM}_{2}\right)$ and a programmed instruction workbook $\left(\mathrm{SIM}_{3}\right)$, were responsible for yielding a significant difference on the reported measure of affective verbal expression.

The results of using the post-hoc Duncan's Multiple Range Test are presented in Table 2. It can be observed that experimental group one lusing the audio-tape and workbook; SIM $_{1}$ ) was not significantly different from both experimental groups two (using the audio-tape only; SIM ${ }_{2}$ ) and three (using the workbook only; SIM $_{3}$ ). Therefore, null hypothesis \#2 was not rejected at the .05 level of significance. 
TABLE 2

DUNCAN'S MULTIPLE RANGE TEST

USING AVE SCORES

\begin{tabular}{crrc}
\hline Grouping & Mean & N & Group \\
\hline A & 12.42 & 14 & 2 \\
B A & 11.41 & 12 & 1 \\
B C & 8.41 & 12 & 3 \\
C & 7.78 & 14 & control
\end{tabular}

Means with the same letter are not significantly different
Alpha $=.05$
$\mathrm{DF}=48$
$M S=13.58$ 
Further evaluation of this post-hoc test indicates that, although not significantly different from each other, experimental group one (using audio-tape and workbook; SIM 1 ) and experimental group two (using audio-tape only; $\mathrm{SIM}_{2}$ ) were significantly different from the control group at the .05 level of significance. The means and standard deviations for the dependent measure affective verbal expression (AVE). are presented in Table 3. Figure 1 is a graphical representation of the treatment means. This figure illustrates that experimental group two (using audio-tape; $\mathrm{SIM}_{2}$ ) had the highest mean and experimental group one (using audiotape and workbook; $\mathrm{SIM}_{1}$ ) had the second highest mean. Experimental group three (using workbook only; $\mathrm{SIM}_{3}$ ) had the third highest mean and was not significantly different from the control group as were experimental groups one and two. The control group yielded the lowest mean.

Basically these results indicate that preclients completing a self-instruction module with an audio-taped simulated counseling session $\left(\mathrm{SIM}_{2}\right)$ or those completing a module that combined the audio-tape with a programmed instruction workbook ( SIM $_{1}$ ) had a significantly higher frequency of affective verbal expression (AVE) in a later counseling session than did the control group.

$$
\mathrm{HO}_{3}
$$

In general, null hypothesis \#3 stated that no statistically significant difference would exist between the experimental groups using the self-instruction modules and 
TABLE 3

MEANS AND STANDARD DEVIATIONS

USING AVE SCORES

\begin{tabular}{crrr}
\hline Group & $\mathrm{N}$ & Mean & SD \\
\hline & 12 & 11.41 & 4.90 \\
2 & 14 & 12.42 & 3.48 \\
3 & 12 & 8.41 & 3.05 \\
control & 14 & 7.78 & 3.12 \\
\hline
\end{tabular}




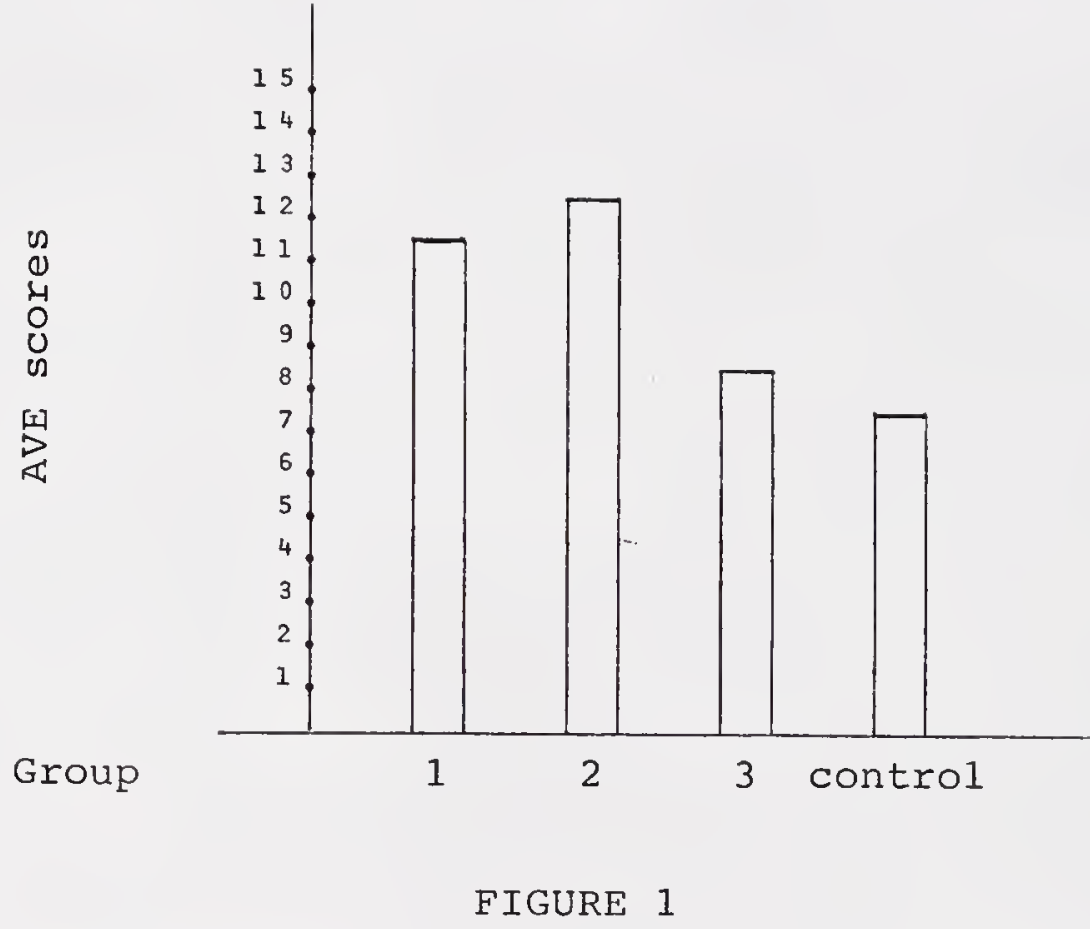

GRAPHICAL REPRESENTATION OF TREATMENT MEANS USING AVE SCORES 
the control group on the dependent measure of specific self-rererent affect (SSRA) during a later counseling session.

The results of the one-way analysis of variance presented in Table 4 indicate that a significant difference was found between the groups on the measure of specific selfreferent affect (SSRA) with an $\mathrm{F}$ of 2.94 and $\mathrm{p}<.05$. Therefore, null hypothesis \#3 was rejected. As analysis of variance does not indicate the direction of the difference, a post-hoc analysis on this measure was performed in order to indicate where the significant difference(s) occurred between the groups. This was tested as stated in null hypothesis \# 4 .

$$
\underline{\mathrm{Ho}}_{4}
$$

There is no statistically significant difference between experimental group one as compared with groups two and three on the dependent measure of SSRA.

The results of using the post-hoc Duncan's Multiple Range Test presented in Table 5 indicated that experimental group one (using audio-tape and workbook; SIM $_{1}$ ) was not significantly different from both experimental group two (using audio-tape only; SIM $_{2}$ ) and experimental group three (using workbook only; $\mathrm{SIM}_{3}$ ) on the dependent measure of specific self-referent affect. Therefore, null hypothesis \#4 was not rejected. However, the post-hoc data analysis 
TABLE 4

ANALYSIS OF VARIANCE

USING SSRA SCORES

\begin{tabular}{lrrrr}
\hline Source of Variation & DF & SS & MS & F \\
\hline Group & 3 & 122.71 & 40.90 & 2.94 \\
error & 48 & 668.84 & 13.93 & \\
Total & 51 & 791.55 & & \\
\hline * $\mathrm{p}<.05$ & & & & \\
\hline
\end{tabular}


TABLE 5

DUNCAN'S MULTIPLE RANGE TEST

USING SSRA SCORES

\begin{tabular}{cccc}
\hline Grouping & Mean & N & Group \\
\hline A & 9.92 & 14 & 2 \\
B A & 9.33 & 12 & 1 \\
B & 6.75 & 12 & 3 \\
B & 6.50 & 14 & control \\
\hline
\end{tabular}

Means with the same letter are not significantly different
Alpha $=.05$
$\mathrm{DF}=48$
MS $=13.58$ 
revealed a somewhat similar pattern as was found with the previous dependent measure of AVE.

This time, only experimental group two was found to be significantly different at the alpha level of .05 from the control group. On the previous measure of AVE both experimental groups one and two were found to be significantly different from the control. Experimental group one (SIM ${ }_{1}$ ) was not found to be significantly different from experimental group two $\left(\operatorname{SIM}_{2}\right)$. This points out a similarity between the effects of SIM $_{1}$ (audio-tape and workbook) and SIM 2 (audiotape only). More specifically, experimental group two (using audio-tape onIy; $\mathrm{SIM}_{2}$ ) was the only group shown to have an increase on the dependent measure of specific selfreferent affect. It is important to note that SIM ${ }_{1}$ (audiotape and workbook) and SIM $_{3}$ (workbook only) were shown to have no significant effects on the dependent measure of specific self-referent affect.

The means and standard deviations for the dependent measure of specific self-referent affect are shown in Table 6. Figure 2, showing a graphic representation of the treatment means, illustrates that experimental group two (audio-tape only; SIM ${ }_{2}$ ) had the highest mean. Experimental group one (audio-tape and workbook; SIM $_{1}$ ) had the second highest, experimental group three (workbook only; SIM 3 ) the third highest and the control group had the lowest mean. This rank order of treatment means is identical to the order that was reported for the previous dependent measure of AVE illustrated in Figure 1. 
TABLE 6

MEANS AND STANDARD DEVIATIONS

USING SSRA SCORES

\begin{tabular}{cccc}
\hline Group & $\mathrm{N}$ & Mean & SD \\
\hline & 12 & 9.33 & 3.87 \\
2 & 14 & 9.92 & 3.84 \\
3 & 12 & 6.75 & 3.74 \\
control & 14 & 6.50 & 3.47 \\
\hline
\end{tabular}




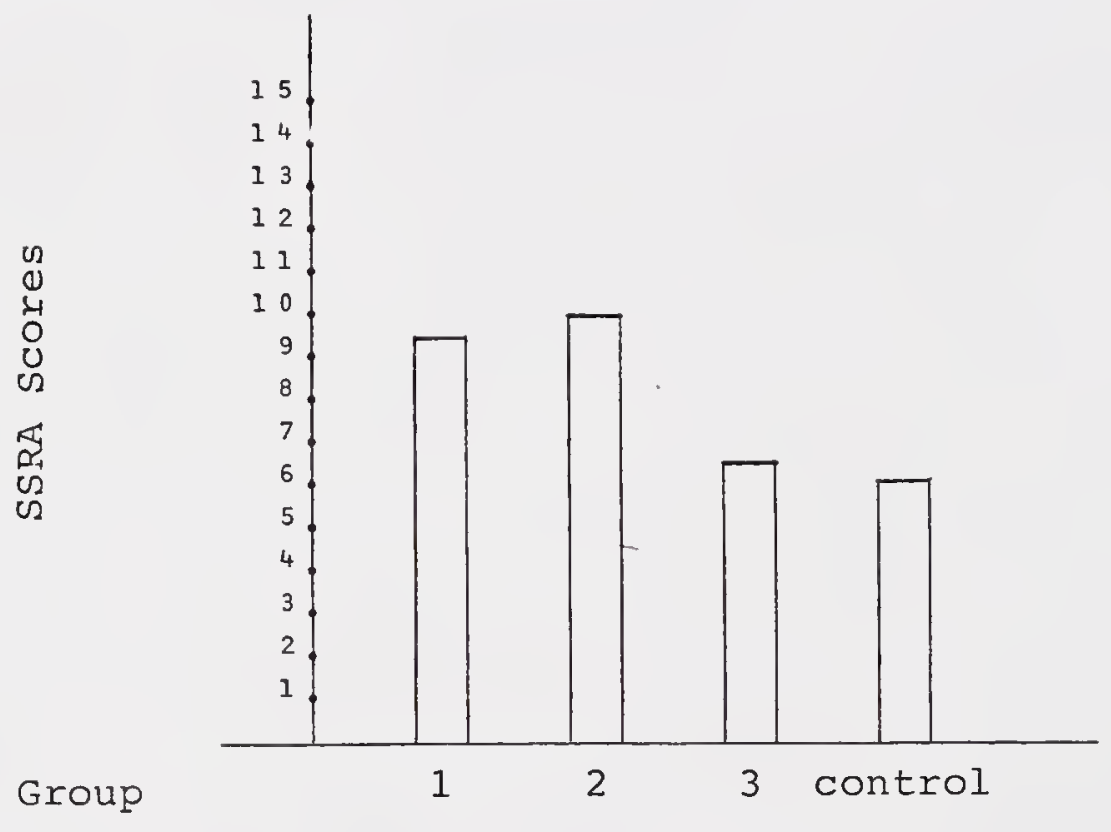

FIGURE 2

GRAPHICAL REPRESENTATION OF TREATMENT MEANS USING SSRA SCORES 


$$
\stackrel{\mathrm{HO}}{5}_{5}
$$

Null hypothesis $\# 5$ indicated that no statistically significant difference would exist between the experimental groups of preclients and the control group on the dependent measure of specific other referent affect (SORA) during a later counseling session.

The results of using a one-way analysis of variance for the dependent measure specific other referent affect are presented in Table 7. These results depart from the previous reported findings indicating that no significant differences were found between the groups on this measure (SORA). The probability of the $F$ statistic for this measure was $\underline{p}=0.27$. Therefore, null hypothesis \#5 was not rejected.

Post-hoc data analysis was run on all dependent variables as a matter of routine in the statistical analysis system used to analyze the data obtained during this investigation even though no significant differences might have been found. Post-hoc analysis on the dependent measure of specific other referent affect was performed to determine where the significant difference(s) occurred (Analysis of variance already indicated that no differences were found). This was tested as stated in null hypothesis \#6.

$$
\underline{H O}_{6}
$$

There is no statistically significant difference between experimental group one as compared with groups two and three on the dependent measure of SORA. 
TABLE 7

ANALYSIS OF VARIANCE

USING SORA SCORES

\begin{tabular}{lrrrr}
\hline Source of Variation & DF & SS & MS & F \\
\hline Group & 3 & 5.38 & 1.79 & 1.32 \\
error & 48 & 65.44 & 1.36 & \\
Total & 51 & 70.82 & & \\
\hline
\end{tabular}

$\star \underline{p}<.05$ 
The results of using Duncan's post-hoc test shown in Table 8 indicate that no significant differences were found between the groups. Therefore, null hypothesis \#6 was not rejected. The means and standard deviations for the dependent measure of specific other referent affect are shown in Table 9 .

Simply, the results indicate that the self-instruction modules used in this study had no effects on the frequency of specific other referent affective statements emitted by preclients in a later counseling session.

\section{$\underline{\mathrm{HO}}_{7}$}

Null hypothesis \#7 stated, in general, that no statistically significant difference would exist between the experimental groups of preclients using the self-instruction modules and the control group on the dependent measure of nonspecific other referent affect (NORA). The results of using the one-way analysis of variance are presented in Table 10. The findings indicated that no significant differences were found between the groups on the measure of NORA. Therefore, null hypothesis \#7 was not rejected. Post-hoc data analysis was performed on the dependent measure of nonspecific other referent affect to indicate where the significant difference(s) occurred (Analysis of variance already indicated that no differences were found). This was tested as stated in null hypothesis \#8. 
TABLE 8

DUNCAN'S MULTIPLE RANGE TEST

USING SORA SCORES

\begin{tabular}{cccc}
\hline \hline Grouping & Mean & N & Group \\
\hline A & 1.42 & 14 & 2 \\
A & 0.91 & 12 & 1 \\
A & 0.83 & 12 & 3 \\
& 0.57 & 14 & control \\
\hline \hline Means with the same letter are not significantly different \\
Alpha $=.05$ & DF $=48$ & & MS $=1.36$
\end{tabular}


TABLE 9

MEANS AND STANDARD DEVIATIONS

USING SORA SCORES

\begin{tabular}{cccc}
\hline Group & N & Mean & SD \\
\hline 1 & 12 & 0.91 & 1.08 \\
2 & 14 & 1.42 & 1.65 \\
3 & 12 & 0.83 & 0.93 \\
control & 14 & 0.57 & 0.75 \\
\hline
\end{tabular}


TABLE 10

ANALYSIS OF VARIANCE

USING NORA SCORES

\begin{tabular}{lrrrr}
\hline \hline Source of Variation & DF & SS & MS & F \\
\hline Group & 3 & 1.07 & 0.35 & 0.31 \\
error & 48 & 55.35 & 1.15 & \\
Total & 51 & 56.42 & & \\
\hline
\end{tabular}

$\underline{p}<.05$ 


\section{$\underline{\mathrm{Ho}}_{8}$}

There is no statistically significant difference between experimental group one as compared with groups two and three on the dependent measure of NORA.

The results of using Duncan's post-hoc test presented in Table 11 indicate that experimental group one was not significantly different from experimental groups two and three. Therefore, null hypothesis \#8 was not rejected. The means and standard deviations for the dependent measure nonspecific other referent affect are presented in Table 12 . More specifically, the results indicate that the the selfinstruction modules, regardless of the type, used in this investigation had no effects on the frequency of nonspecific other referent affective statements emitted by the experimental group subjects as compared with the control group subjects in a later counseling session.

\section{Summary of the Results}

Three different self-instruction modules were investigated for their effects on four dependent variables: affective verbal expression (AVE), (2) specific self-referent affect (SSRA), (3) specific other referent affect (SORA) and, (4) nonspecific other referent affect (NORA). The eight hypotheses generated by these variables were tested using analysis of variance and the direction of the significant difference(s) was tested post-hoc using Duncan's Multiple Range Test. Both statistical tests 
TABLE 11

DUNCAN'S MULTIPLE RANGE TEST

USING NORA SCORES

\begin{tabular}{cccc}
\hline Grouping & Mean & N & Group \\
\hline A & 1.25 & 12 & 1 \\
A & 1.07 & 14 & control \\
A & 1.00 & 14 & 2 \\
A & 0.83 & 12 & 3 \\
\hline
\end{tabular}

Means with the same letter are not significantly different Alpha $=.05$

$D F=48$

$M S=1.15$ 
TABLE 12

MEANS AND STANDARD DEVIATIONS

USING NORA SCORES

\begin{tabular}{cccc}
\hline Group & $\mathrm{N}$ & Mean & SD \\
\hline 1 & 12 & 1.25 & 0.89 \\
2 & 14 & 1.00 & 1.10 \\
3 & 12 & 0.83 & 0.83 \\
control & 14 & 1.07 & 1.32 \\
& & & \\
\hline
\end{tabular}


utilized a rejection level of $\underline{p}<.05$. It was found that a self-instruction module utilized by clients prior to receiving counseling which combined a simulated audio-taped counseling session and a programmed instruction workbook, or a self-instruction module with the audio-tape only were effective in significantly increasing the frequency of affective verbal expression emitted by a client in a later counseling session when compared to a control group.

It was also found that a self-instruction module utilizing an audio-tape only was effective in significantly increasing clients' emitted frequency of specific selfreferent affect in later counseling. No other significant results were generated, indicating that the self-instruction modules used in this study had no significant effects on the frequency of specific other referent affect or nonspecific other referent affect emitted by the clients in a later counseling session. 


\section{CHAPTER V}

\section{DISCUSSION AND IMPLICATIONS}

Individuals who seek help through counseling will often experience varying time intervals after they initially request counseling and before they actually meet face to face with a counselor for their first formal counseling session. Is there some way in which counselors might capitalize on this sometimes unavoidable delay for the positive assistance of their clients prior to counseling? And, might there be some intervention that would assist these individuals to be "better" clients and possibly experience a more successful encounter in counseling? This study addresses these two questions.

The purpose of this investigation was to study the effects of three self-instruction modules. The aim of the modules was to prepare clients for counseling during the interval prior to actual counseling by teaching them two communication skills for positive growth within the forthcoming counseling relationship: (1) affective verbal expression and, (2) the concreteness of their verbally expressed affect. More specifically, this study examined the effects of programmed instruction via a written selfinstruction workbook and modeling via an audio-taped simulated counseling session on the dependent measures of 
affective verbal expression, specific self-referent affect, specific other referent affect, and nonspecific other referent affect. As described in chapter III, affective verbal expression was defined as the total count of affective words or phrases emitted by the client during an audio-taped 15-minute analyzed segment of the client's first counseling session. Concreteness was operationally defined as an increase in the frequency of specific self-referent affect and a concomitant decrease in the frequency of the client's specific other referent affect and nonspecific other referent affect. A total of 52 subjects volunteered for this study.

\section{Summary of the Findings}

Eight hypotheses were tested in order to locate significant differences between the three experimental groups and the one control group on the four dependent measures. Using analysis of variance and post-hoc Duncan's Multiple Range Test, two of the eight hypotheses were rejected at the alpha level of $\underline{p}<.05$, one at the $\underline{p}<.005$ level of significance.

Basically, the results indicated that the combined techniques of programmed instruction and modeling or modeling alone, as used in this study, were effective pretraining techniques for increasing the frequency of affective verbal expression emitted by clients in a later counseling session. On the dependent measure of specific self-referent affect, only modeling via an audio-taped simulated counseling session was shown to significantly 
increase the frequency of this measure. The dependent measures of specific other referent affect and nonspecific other referent affect were not significantly effected by the self-instruction modules used. In general this indicates that two of the three self-instruction modules achieved the desired effects of increased affective verbal expression but had no effects positive or negative on the concreteness of the clients verbally expressed affect.

\section{Discussion}

The results of this study, on the whole, parallel the findings of the numerous investigations utilizing the various modes of pretraining clients for counseling. These studies have shown varying results as did the current investigation. The results of this study confirm the findings of Green and Marlatt (1972) who found that modeling and direct instructions would increase the frequency of affective verbalizations. This current investigation utilized a unique format for the audio-taped presentation of a client modeling desirable counseling communication. The uniqueness was that the audio-tape model not only demonstrated desirable communication behaviors but also demonstrated undesirable client counseling communication. The direct instructions and the format of the presentation (two distinct back to back examples, desirable and undesirable) drew attention to this difference and were designed to increase the frequency of the desirable modeled communication behaviors and decrease the frequency of the undesirable counseling communication with 
clients in a later counseling session. The positive results of this deliberate design were borne out by the results of this current study.

The results of this investigation clearly indicate that the programmed instruction workbook developed especially for this study was by itself ineffective in producing any changes in the frequency of the four dependent measures emitted by the clients in a later counseling session. These findings are somewhat contrary to those found by Maurer (1976). However, Maurer investigated the effects of programmed self-instruction on the facilitative communication skills of elementary school teachers in a teaching environment. obviously there are great differences between clients in a counseling environment and elementary school teachers in a teaching environment. It may be this difference that accounts for the ineffectiveness of the programmed selfinstruction on the dependent measures investigated in this current study.

The results of this current study also confirm the findings of Myrick $(1968,1969)$ who showed that modeling would increase the frequency of high school students' emission of first person pronouns since specific self-referent affect was defined as the frequency of first person pronouns used in conjunction with affective words and or phrases.

\section{Implications}

(1) The results of this study clearly demonstrated the success of modeling as a pretraining technique to increase 
the frequency of a client's affective verbal expression and specific self-referent affect in a later counseling session. More importantly, the unique modeling presentation format was shown to be effective.

(2) It was shown that the modeling and programmed instruction used in this study had no significant effects on clients' emission of specific other referent affect and nonspecific other referent affect, thus revealing no positive effects on the concreteness of the clients' verbalized affect.

(3) This study reveals that pretraining for counseling is an effective and viable intervention which can be used to assist the clients of those counselors who believe in the importance of a client expressing his/her feelings.

(4) The limitations of the programmed instruction workbook were made evident by the results of this study. Its effects at this point are unclear as post-hoc data analysis showed that the group using the workbook only was similar to a group that was, and one that was not, significantly different from the control group.

\section{Recommendations for Future Research}

(1) Systematic replication of this study would be useful to test for the specific effectiveness of the format of the audio-taped modeling used in this study. A similar research design could be adopted that separates the audio-tape into its two main components. 
(2) Systematic replication of this investigation with the added research component of the subjects' evaluation of the helpfulness of the experimental program would provide information on the wider scope of the program's practical value.

(3) Systematic replication of this study with the added research dimension of the counselors evaluation of the subjects' communication behaviors would provide meaningful information on the counselors perception of the effectiveness of the program.

(4) Follow-up research that focuses on such issues as client length of counseling, premature termination, or general success in counseling would provide answers to the questions regarding the overall worthiness in using a pretraining experience.

(5) Regarding the limitations of the written programmed instruction workbook used in this study, there is an assumption held by this investigator relative to the subjects level of personal involvement with the workbook based on the users attractiveness to the workbook. Basically that assumption states that the attractiveness of a self-instruction workbook is an important variable to be considered relative to the overall effectiveness of the module.

It might be that a written programmed instruction workbook is a relatively boring and overused medium of instruction, especially when one considers the sophistication of today's college students. Computerization is currently 
one of the most exciting and powerful modes of instruction and of late it is becoming more affordable to the lay person. A programmed self-instruction workbook lends itself ideally to the format and logic of a computer. Adapted to a computer presentation with interactive capabilities would thus increase a module's attractiveness and power of self-instruction. Systematic replication of this study with an improved self-instruction module via computer technology is the next step toward the overall increased efficiency of pretraining clients for counseling.

\section{Limitations}

Research in the behavioral sciences contains, as in any investigation, certain inherent limitations that may effect the results of the study.

The first limitation in this study is concerned with the nature of the experimental design. The randomized control group, post-test only design was chosen as pretesting (in this case counseling) would contaminate the effects of the treatment used. This basic design implies that subjects are equivalent through randomization. However, randomization does not guarantee equivalency.

The second limitation involves the use of university students for the experimental population. The results are therefore limited in their generalizability to those individuals with similar educational and socio-economic backgrounds. 
APPENDIX A

INFORMED CONSENT FORM

Self-instruction Module study

As a student at the University of Florida/Bradley University you may or may not have participated in a research study. This letter is written to request your participation in a study here at the University counseling center. If you agree to participate in this study, the receptionist will give you a self-instruction module to take home and complete before you return for your first counseling session. This module is designed to help you in counseling as it will orient you to the process of counseling and teach you basic communication skills useful during counseling. It should take you less than 1.5 hours to complete the module.

In order to measure the results of the module it will be necessary to audio-tape record only your first counseling session. Please understand that ALL INFORMATION OBTAINED DURING THIS STUDY WILL BE HELD IN THE STRICTEST OF CONFIDENCE. Confidentiality is a must as your counseling is a personal matter. Confidentiality will be provided and maintained to the fullest extent of the law. For data purposes, only this investigator and two graduate students (to be named at a later date) will have access to the audio-tapes. The audio-tapes will be magnetically erased after the data are 
recorded following your first counseling session here at the center.

I have read and I understand the procedure described above. I agree to participate in the procedure and I have received a copy of this description.

Signatures:

\section{CLIENT}

WITNESS

Daniel E. Shaw

Project investigator's

name and address.

Daniel E. Shaw

University of Florida

311 Little Hall

Gainesville, FL 32611

(904) 392-1575

( ) Check here if you would like to receive a summary of the research project. 


\section{APPENDIX B \\ CONTROL GROUP INFORMATION}

Thank you for your participation. You have been assigned to what is called the control group. You will not receive the self-instruction module until after you have completed your first counseling session. It is not required that you take the self-instruction module; I feel certain, however that you will find it useful for future counseling sessions.

Thank you

Daniel E. Shaw

University of Florida

311 Iittle Hall

Gainesville, FI 32611

(904) 392-1575 


\section{APPENDIX C TAPESCRIPT OF AUDIO-TAPE (SIM 2$)$}

This module has been developed to assist you as a client before you enter counseling. It is not a substitute for counseling. It is designed to help you learn a special way to communicate your concerns with a counselor. This module is not designed to resolve your concerns, al though it may bring you closer to your concerns by involving you with them in this special way

This module will help you to learn two basic communication skills that have been shown to be necesary for effective communication in a counseling relationship. That which you will learn will assist you and your counselor in helping you reach a satisfactory resolution of your concerns. The two communication skills that you will become more familiar with are: the specific and accurate expression of your feelings and specific as opposed to vague verbal communication.

The counseling relationship is based upon two people sharing their thoughts, ideas, and feelings. The more you as a client share your feelings with a counselor, the more that your counselor can understand and help you. Expressing your feelings will also assist you toward a better understanding of your concerns. 
Speaking in specific terms with a counselor is important too. Being specific involves speaking in a concrete and direct manner as opposed to being vague and elusive. obviously, the more specific you communicate the easier it will be for you and your counselor to understand your concerns and thus reach solutions.

This module will assist you to identify and practice, feeling oriented and concrete communication which you are encouraged to demonstrate during your counseling session.

The remainder of this audio-tape consists of two simulated counseling sessions. You will hear both good and poor client communication. In the first section you will notice that the client is most vague and unspecific about her situation and her own feelings. In fact she only alludes to her own feelings. She rarely expresses her feelings to the counselor. Listen carefully as the client begins. client: How ya doing?

Counselor: I've been fine. How are you?

Cl: OK, I guess.

Co: Not too good.

Cl: Well, remember that person I told you that I moved in with a while back, and that things were going real good and al1?

Co: Yes.

Cl: Well um - . I went home over break and I was having a good vacation and I get this little phone call and it's my Mom. She says, "Your roommate has been trying 
to get a hold of you." so I said, "Oh wow!" What was wrong. So I called her up and she said to me, "I found a cheaper place to live and I'm moving out and I'm turning off the utilities and your going to have to find someone." Or what ever. . . She's leaving me with the whole thing.

Co: Just dumped right on you.

Cl: She didn't give me hardly any notice at all.

Co: Sounds like your angry with her.

cl: . . But I can't. . . You know? . . I'm not used to telling people, "Ooooh I'm peaved with youoooo." so I didn't say anything. . . I can't believe she did that.

Co: You're not coming out and telling her but inside you're mad.

Cl: (nervous laughter) Ha ha ha.

Co: I guess your also wondering what your going to do now. Cl: (big sigh) Tell me about it! Ha ha ha, well I. You know? I've been looking in the paper and stuff and I know some folks who will let me stay with them and. - . You know? . . She doesn't even realize what she did to me. (imitates ex-roommate) "This is good for me but I don't care about you. . . You know? You gotta put down the deposits and I'm turning off the electricity and that will be just too tough for you." You know?

Co: She's treated you poorly. 
Cl: - - I didn't expect that from her cause I thought she liked me and, and nobody. . . I don't think it's right that if you get a good deal like that. - But you just don't walk out on someone like that.

Co: Sounds like you feel bad and let down by her.

Cl: - . I'd like to tell her but. You know? . . I don't want to get into a hassle. I'd like to - . just do it, but she's the type of person who can make it hara for you to talk to. You know what I mean?

Co: You believe you don't have a good way of telling her how you feel without some heavy consequences dropping on you.

Cl: Like she's slapped some boys for practically nothing. she may try something with me. . . You know? . . I don't want to... uh.

Co: You're actually afraid of her.

Cl: She's always telling me how she gets even with people and goes, (imitates) "Ha ha ha." You see the whole thing is I owe her some money and since the contract's been broken I'm going to have to get someone else. She walked out, so I'm not about to give her the money when she's the one in the first place. I'll pay one of the bills but she'll. . . She can get like the mafia. . . You know?

Co: You're afraid of what she might try to do to you 
about that. You're determined not to give it back to her.

Cl: NOPE!

Co: But your worried about what may happen.

Cl: I don't want to get into it with her or make a big scene or anything. I'd just like to sort of explain to her that she gave me a bad deal and that I'm not cheating her by not giving her the money cause in essence I don't owe her anything. . . You know? She's the one who broke the contract in the first place and I don't know how to explain that and I don't know if I'm going to get a place to live. It's really crummy. . . Like, I had to come back from vacation and uh. (sigh) This is like my second to last quarter and I have all these things going on now.

Co: It's just a whole lot more pressure that you don't need right now.

Cl: . . And she. . . It's like I didn't deserve it. Why did she, she could have. . . Oh sure she got a good deal and all but where does that leave me. It's like she has given all of her problems to me and she figured that, . . "I can do it!" But she didn't ever think. . . She just called me up like that.

Co: Uh huh. What if you. . . What have you thought about doing about finding a place to live?

Cl: (sigh) Well I'm just going to look around and stuff cause all of my old friends. That's the thing. All 
of my friends are already living in places. You know? So I'm just going to have to look around and end up living with someone I don't even know.

Co: Sounds like your not happy about that at all.

Cl: Yeah? . . Cause I, . . I don't like to move around just cause of the fact that moving is such a pain. But, then again I might be able to find some place that's better than what I have now and maybe cheaper too. In a way it might be a blessing in disguise. What should I do now? Should I just come out and tell her. You know? I think this is really nasty of her. . . I don't want. . . I don't know what to do. . - I don't know whether to go in during the middle of the night and move all of my things to my friends so I don't have to see her or whatever? . . This is such a pain.

Co: If you weren't concerned about the consequences about what she'd do, what would you like to tell her?

Cl: Ha ha ha ha. . . To stick it up her nose! Ha ha ha. Now listen to the same situation. This time notice how her communication is clearer, more specific and full of words and phrases which clearly express her feelings.

$\mathrm{Cl}$ : How ya doing?

Co: Oh I'm fine thanks. How about you?

$\mathrm{Cl}$ : I'm really aggravated and upset.

Co: You do sound angry. What's happening?

$\mathrm{Cl}$ : Well, do you remember that new roommate that I told you 
I moved in with back in January, and how we were getting along so well?

Co: Yes.

Cl: Well when I was home over spring break, enjoying myself, my mother tells me that my roommate had been calling me. Mom didn't say much else, so I got real concerned and called my roommate up immediately. So my roommate informs me that she has found a cheaper place to live and that she is moving out in four days and is having the utilities turned off. . . I'm so mad at her. I'm left having to pay all the rent, move out, or find another roommate, reconnect the utilities and shell out for the deposits. My whole break was ruined. I'm still upset too.

Co: She just dumped on you.

Cl: Yeah, I'm outraged. Just four days notice!

Co: You're really furious with her.

Cl: I am furious . . and surprised! You know? I'm embarrassed to tell you but I'm scared to tell her how angry and insulted I am. I'm really on the spot now too with these housing obligations.

Co: You're not coming out and telling her, but on the inside your seething.

Cl: Yeah. I'm angry and really on the spot too. Co: I guess your also wondering what your going to do now. Cl: (big sigh) I'm so pressured. . . I've been looking in the paper, frantically making calls and putting up 
notices. . . The one thing I feel good about is that my friends have reassured me that they will put me up if necessary. . . . I can't believe her, I feel so used.

Co: Taken advantage of . . and she treated you so shabbily.

Cl: I thought she liked me. . . I'm hurt and let down! We had an agreement and she broke it as if I wasn't worth the effort. I wouldn't treat anyone like she aid me.

Co: Sounds like you feel unimportant and rejected.

Cl: Yes I sure do! I'd like to tell her that but I'm afraid of getting into a fight with her. I'm certain she wouldn't be civil with me. I'm suspicious of her motives. . . She could easily get vicious.

Co: You're unsure of how to talk to her without some heavy consequences dropping on you.

Cl: I'm definitely leary of her. . . I've heard stories of how she slapped an old boy friend right in the face.

Co: You're actually afraid of her.

Cl: I'm afraid of her physically. . . . I remember her telling me how she enjoyed getting even with some old ex-friends. You see, I owe her for the last months rent and I feel so burned by her that I think I have the right to keep that money. Oh, I'll pay her for my share of the utilities. I'm not that spiteful. But I'm really fearful that she'll lean on me like the mafia. 
Co: You're afraid of what she might try to do to you. You're determined not to give her the rent money back.

$\mathrm{Cl}:$ Exactly

Co: You seem worried about what may happen between you two. Cl: I really dislike arguing with anyone and especially her. I feel correct in keeping the money. I'd like to calmly explain to her that I feel betrayed by her and I think she ought to understand that. I'm reluctant to talk with her. . . I'm so disappointed about how my vacation was ruined. I don't know what to do about a place to live.. ( $(\mathrm{sigh})$. This is my next to the last quarter before I graduate and I don't need to feel this pushed and pulled right now.

Co: You've got more pressure that you know you don't want or need.

$\mathrm{Cl}$ : What puzzles me is trying to figure out why she did this. . . I didn't deserve to be treated so poorly and what hurts me is how easy this seemed for her to do to me. She didn't even think of me.

Co: You seem overwhelmed by how she treated you. . . . I wonder what you have been thinking about in terms of finding a place to live.

Cl: (sigh) Well,.. I'll have to resort to looking in the paper. I'm all alone in this, all my friends already have places. I'm nervous about the possibility of living with strangers.

Co: Moving into a new place with strangers can feel odd. 
Cl: I'm not too happy about the idea of having to move. I dislike moving . . but . . then again, I might be able to find some place closer to school which I don't have now . . and maybe even someplace cheaper. I was thinking . . I'm upset now sure, but maybe this is a blessing in disguise. . . I'm torn between telling my ex-roommate how angry $I$ am and just wanting to avoid her completely. I'm really upset over how she treated me.

Co: If you weren't worried about the consequences about what she'd do,.. . what would you like to tell her? $\mathrm{Cl}$ : Ha ha ha ha. To stick the rent money up her nose. Ha ha ha.

Hear the differences between the two sessions. Listen to them again if you like. When you are done your task will be to imagine yourself talking with a counselor. Try to express you concerns in your own style but remember to be as specific as you can and to do your best at expressing your feelings freely. When you have your counseling appointment demonstrate this communication skill. (end of tape) 


\section{APPENDIX D \\ PROGRAMMED INSTRUCTION WORKBOOK (SIM 3$)$}

This is a programmed instruction workbook. All of the entries you make in this workbook will be kept strictly confidential. The workbook will be destroyed by the primary investigator when it is turned in following your counseling appointment. Please be sure to bring it with you when you arrive at the counseling center to insure its return. Thank you. 
This module has been developed to assist you as a client before you enter counseling. This module is not a substitute for counseling. It is designed to help you to learn a special way to communicate your concerns with a counselor. This module is not designed to resolve your concerns, although it may bring you closer to your concerns by involving you with them in this special way.

This module will help you to learn two basic communication skills that have been shown to be necessary for effective communication in a counseling relationship. What you will learn will assist you and your counselor in helping you reach a satisfactory resolution of your concerns. The two communication skills that you will become more familiar with are: the specific and accurate expression of your feelings and specific as opposed to vague verbal communication.

The counseling relationship is based upon two people sharing their thoughts, ideas and feelings. The more you as a client share your feelings with a counselor the more that counselor can understand and help you. Expression of your feelings will also assist you toward a better understanding of your concerns.

Speaking in specific terms with a counselor is important too. Being specific involves speaking in a concrete and direct manner as opposed to being vague and elusive. Obviously, the more specific your communication is, the easier it will be for you and your counselor to understand you. 
This module will assist you to identify and practice, feeling oriented and concrete communication which you are encouraged to utilize and demonstrate during your counseling session.

Read the directions for each question carefully. Begin with \#1 and complete each item before you begin the next.

\# I Using as much or as little of the space provided below, please describe the concern(s) that you have come to discuss with a counselor. Write as if you were speaking directly to a counselor. Don't worry about spelling. This is for your practice. 
\#2 Now look back over your response for \#1. Briefly think about how you have stated that which you did in regards to the feelings and experiences you had about this situation. Where the feelings pleasant, unpleasant or both?

\#3 What feeling words did you use in \#1? Circle them and list them below putting a check next to the last one.

\#4 Now going back to your response to \#1, think about your concerns again. Look to see if you left out any words that might better or more completely describe how you felt and/or still feel with this concern. Ask yourself, "How did I feel in that situation, towards the people, about the ideas, about myself, or the situation in general?" "How do I feel about it now?"

\#5 Go back to \#3 and add any words which fit your experience. \#6 Now turn to the last page in this workbook to where the feeling vocabulary 1 ist begins.

\#7 Look at both the feeling vocabulary and your 1 ist in \#3. Thinking about your concerns, are there any words which you could add or change in order to more accurately and specifically describe how you feel?

GO TO NEXT PAGE 
\#8 Add as many new words as you can. Add at least one or two new words. Use the space below.

\#9 Count all the feeling words that you have used in \#3 and \#9. Put the total number of words here. $\rightarrow$

\#10 Now in the space provided below briefly describe the concern in \#1 as if you were speaking with a counselor. This time use as many feeling words as is appropriate to accurately, specifically, and completely express your concern. 
\#11 Look back over your response to \#10 and circle the feeling words you have used. Is there anything you want to add or change that will more accurately and specifically describe how you feel? If yes, do so in the space provided below. 
$\# 12$ Look back at your last response (\#10 or \#12). Think about the specificity of the communication. That is, have you stated your concern clearly. Will another person recognize the way in which you choose to express your feelings? How else can you make the communication more specific, to the point, relatively accurate, and concise?

Here are some suggestions:

Does anything look ar sound vague as you re-read your last response?

Did you use the words you, they, us, we, or it, when your really meant I or $\mathrm{ME}$ ?

Did you express your feelings, using specific feeling words?

\#13 Go back to your last response and look to see what changes you can make after asking yourself the above questions.

\#14 Now for the last time. Re-ivrite your concern using the space provided on the next page in $\# 15$. You should make as many changes as you can to make the communication more specific. Remember, express your feelings using as many feeling words as apply for you. 
\#15 Use the space below for your final re-write.

\#16 Compare your response in \#1 with \#15. Notice the differences. Your task is to now demonstrate what you have learned from this module during your counseling session. Remember to express your feelings often during the session and be as specific and concrete as you know how. 
Love, Affection, Concern

admired
adorable
affectionate
agreeable
altruistic
amiable
benevolent
benign
big-hearted
brotherly
caring
charitable
comfortable
congenial
conscientious
considerate
cooperative
cordial
courteous
dedicated
devoted
easy-going
empathetic
fair
faithful
forgiving
friendly

amused

at ease

blissful

brilliant

calm

cheerful

comical

contented

delighted

ecstatic

elevated

enchanted

enthusiastic

excellent

fantastic

generous
genuine
giving
good
good-humored
good-natured
helpful
honest
honorable
hospitable
humane
interested
just
kind
kind-hearted
lenient
lovable
loving
mellow -
mild
moral
neighborly
nice
obliging
open

optimistic patient peaceful pleasant polite reasonable receptive reliable respectful responsible sensitive sweet sympathetic tender thoughtful tolerant truthful trustworthy understanding unselfish warm warm-hearted well-meaning wise

majestic marvelous overjoyed pleasant pleased proud satisfied serene splendid superb terrific thrilled tremendous triumphant vivacious 
Potency

$\begin{array}{ll}\text { able } & \text { energetic } \\ \text { adequate } & \text { fearless } \\ \text { assured } & \text { firm } \\ \text { authoritative } & \text { forceful } \\ \text { bold } & \text { gallant } \\ \text { brave } & \text { hardy } \\ \text { capable } & \text { healthy } \\ \text { competent } & \text { heroic } \\ \text { confident } & \text { important } \\ \text { courageous } & \text { influential } \\ \text { daring } & \text { intense } \\ \text { determined } & \text { lion-hearted } \\ \text { durable } & \text { manly } \\ \text { dynamic } & \text { mighty } \\ \text { effective } & \text { powerful }\end{array}$

Unpleasant Affective States robust

secure

self-confident self-reliant

sharp

skillful

spirited

stable

stouthearted

strong

sure

tough

virile

well-equipped

wel1-put-together

Depression
abandoned
alien
alienated
alone
annihilate
awful
battered
bruised
blue
burned
cast off
cheapened
crushed
debased
defeated
degraded
dejected
demolished
depressed
despair
despised
despondent
destroyed
discarded
discouraged
disfavored
dismal

done for
down cast
downhearted
downtrodden
dreadful
estranged
excluded
forlon
forsaken
gloomy
glum
grim
hated
hopeless
horrible
humiliated
hurt
in the dumps
kaput
left out
loathed
lonely
lonesome
lousy
low
miserable
mishandled

mistreated

moody

mournful

obsolete

ostracized

out of sorts

overlooked

pathetic

pitiful

rebuked

regretful

rejected

reprimanded

rotten

ruined

run down

sad

stranded

terrible

unhappy

unloved

valueless

washed up

shipped

worthless

wrecked 


afflicted
anguished
at the feet of
at the mercy of
awkward
badgered
bewildered
blameworthy
clumsy
confused
constrained
disgusted
disliked
displeased
dissatisfied
distrustful
disturbed

Fear, Anxiety doubtful

foolish

Eutile

grief

helpless

$h$ indered

impaired

impatient

imprisoned

lost

nauseated

offended

pained

perplexed

puzzled

ridiculous

sickened

hesitant

horrified

ill at ease

insecure

intimidated

jealous

jittery

jumpy

nervous

on edge

overwhelmed

panicky silly

skeptical

speechless

strained

suspicious

swamped

the plaything of

the puppet of

tormented

touchy

ungainly

unlucky

unpopular

unsatisfied

unsure restless
scared
shaky
shy
strained
tense
terrified
terror-stricken
timid
uncomfortable
uneasy
worrying

poked fun at

pooh-poohed

pulled to pieces

put down

ridiculed

roasted

scoffed at

scorned

shamed

slammed

slandered

underestimated 
Impotency, Inadequate

anemic
broken
broken down
chicken-hearted
cowardly
crippled
debilitated
defective
deficient
demoralized
disabled
effeminate
exhausted
exposed
feeble
flimsy
fragile
frail
harmless

helpless

impotent

inadequate

incapable

incompetent

indefensible

ineffective

inefficient

inept

inferior

infirm

insecure

insufficient

lame

maimed

meek

nerveless

paralyzed

powerless

\author{
puny \\ shaken \\ shaky \\ sickly \\ smal 1 \\ strengthless \\ trivial \\ unable \\ unarmed \\ uncertain \\ unfit \\ unimportant \\ unqualified \\ unsound \\ unsubstantiated \\ useless \\ vulnerable \\ weak \\ weak-hearted
}

Anger, Hostility, Cruelty

\author{
aggravated \\ agitated \\ aggressive \\ angry \\ annoyed \\ antagonistic \\ arrogant \\ austere \\ bad-tempered \\ belligerent \\ bigoted \\ biting \\ bloodthirsty \\ blunt \\ bullying \\ callous \\ cantankerous \\ cold-blooded \\ combative \\ contrary \\ cool \\ corrosive \\ cranky \\ critical \\ cross \\ cruel \\ dictatorial
}

$\begin{array}{ll}\text { discontented } & \text { obstinate } \\ \text { dogmatic } & \text { opposed } \\ \text { enraged } & \text { oppressive } \\ \text { envious } & \text { outraged } \\ \text { fierce } & \text { perturbed } \\ \text { furious } & \text { poisonous } \\ \text { gruesome } & \text { prejudiced } \\ \text { hard } & \text { pushy } \\ \text { hard-hearted } & \text { rebellious } \\ \text { harsh } & \text { reckless } \\ \text { hateful } & \text { resentful } \\ \text { heartless } & \text { revengeful } \\ \text { hellish } & \text { rough } \\ \text { hideous } & \text { rude } \\ \text { hostile } & \text { ruthless } \\ \text { hypercritical } & \text { sadistic } \\ \text { illtempered } & \text { savage } \\ \text { impatient } & \text { severe } \\ \text { inconsiderate } & \text { spiteful } \\ \text { inhuman } & \text { stern } \\ \text { insensitive } & \text { stormy } \\ \text { intolerable } & \text { unfeeling } \\ \text { intolerant } & \text { unfriendly } \\ \text { irritated } & \text { unmerciful } \\ \text { mad } & \text { unruly } \\ \text { malicious } & \text { vicious } \\ \text { mean } & \text { vindictive }\end{array}$


APPENDIX E

SUPPLEMENTAL INSTRUCTIONS

Please return all materials in this envelope to the receptionist when you arrive at the counseling center for your appointment.

It is important that you not discuss the self-instruction modules with your counselor until the study is completed because this information may bias the results of the study. This should in no way effect your success in counseling. Thank you. 


\section{APPENDIX F}

SUPPLEMENTAL INSTRUCTIONS

LISTEN TO AUDIO-TAPE FIRST 


\section{REFERENCES}

Bandura, A. Influence of models reinforcement contingencies on the acquisition of imitative responses. In $A$. Bandura (Ed.), psychological modeling: Conflicting theories. Chicago: Aldine Atherton, 1971.

Bandura, A. The role of modeling processes in personality development. In C. S. Lavatelli, \& F. Standler (Eds.), Readings in child behavior and development (3rd ed.). New York: Harcourt Brace Jovanovich, 1972.

Bandura, A. Social learning theory. Englewood Cliff, New Jersey: Prentice-Hall, 1977.

Buscaglia, L. Love. New York: Fawcett Crest, 1972.

Carkhuff, R. R. Helping and human relations: Selection and training (Vol. 1). New-York: Holt, Rinehart \& Winston, 1969 .

Carkhuff, R. R. The development of human resources. New York: Holt, Rinehart \& Winston, 1971.

Carkhuff, R. R. The art of helping. Amherst, Mass.: Human Resource Development Press, 1972.

Cartwright, M. H. A preparatory process for group counseling and or group therapy (Doctoral dissertation, University of Tennessee, 1972). Dissertation Abstracts International, 1972, 33, 2315-B.

Combs, A. W. Counseling as a learning process. Journal of Counseling Psychology, 1954, 1(1), 31-36.

Combs, A. W. Avila, D. L., \& Purkey, W. W. Helping Relationships: Basic concepts for the helping profession (2nd ed.). Boston: Allyn \& Bacon, 1978 .

Combs, A. W., Richards, A. C., \& Richards, F. Perceptual psychology: A humanistic approach to the study of persons. New York: Harper \& Row, 1976

Combs, A. W., \& Snygg, D. Individual behavior: A perceptual approach to behavior (Rev. ed.). New York: Harper \& Row, 1959 . 
Dankowski, R. A. The effects of model type and model mode upon self-disclosure (Doctoral dissertation, University of Arizona, 1976). Dissertation Abstracts International, $1976, \underline{37}, 130-131-\mathrm{A}$.

DelBeato, D. J. The effects of one type of preinterview verbal discrimination training model on verbal behavior in an initial interview setting (Doctoral dissertation, University of Maryland, 1971). Dissertation Abstracts International, $1972,32,3682-\mathrm{B}$.

Egan, G. The skilled helper: A model for systematic helping and interpersonal relating. Belmont, Calif.: wadsworth, 1975 .

Fernbach, R. Preparation of clients for individual psychotherapy using a written document to orient expectations and indicate appropriate behaviors (Doctoral dissertation, Ohio University, 1974). Dissertation Abstracts International, $1975, \underline{35}, 6092-6 \overline{093-B}$.

Fromm-Reichman, F. Principles of intensive psychotherapy. Chicago: The University of Chicago Press, 1950.

Galdaleto, A. F. Differential effects of fidelity in client pretraining on client anxiey, self-disclosure, satisfaction and outcome (Doctoral dissertation, University of Virginia, 1976). Dissertation Abstracts International, $1976,37,2503-B$.

Gazda, G. M., Asbury, F. R., Blazer, F. J., Childers, W. C., \& Walters, R. P. Human relations development (2nd ed.). Boston: Allyn \& Bacon, 1977.

Gelso, C. J., Brooks, L., \& Karl, N. J. Perceptions of counselors and other helpers: A consumers analysis. Journal of College student Personnel, 1975, 16(4), 287-292.

Goldstein, A. P. Therapist/patient expectations in psychotherapy. New York: Pergamon Press, 1962.

Goldstein, D. J. Client pretherapy preparation effects on the reduction of incongruent therapeutic expectancies (Doctoral dissertation, University of North Colorado, 1976). Dissertation Abstracts International, 1977, 37, $6950-\mathrm{A}$.

Green, A. H. \& Marlatt, G. A. Effects of instructions and modeling. upon affective and descriptive verbalization. Journal of Abnormal Psychology, 1972, 80 (2), 189-196.

Greenwald, H. My philosophy of psychotherapy. Journal of Contemporary Psychotherapy, 1973, 6 (1), 29-34. 
Hayakawa, S. I. Through the communication barrier. New York: Harper \& Row, 1979.

Hemmerich, I. E. The effects of modeling on psychotherapy with the use of video-tape pretraining therapy film combining both didactic and modeling techniques (Doctoral dissertation, Illinois Institute of Technology, 1976). Dissertation Abstracts International, 1976, 37, 1878-B.

Higgens, D. L., Ivey, A. E., \& Uhlemann, M. R. Media Therapy: A programmed approach to teaching behavioral skills. Journal of Counseling Psychology, 1970, 17(1), 20-26.

Hoehn-Saric, R., Frank, J. D., Imber, S. D., Nash, E. H., Stone, A. R., \& Battle, C. C. Systematic preparation of patients for psychotherapy, I. Effects on therapy behavior and outcome. Journal of Psychiatric Research, $1964, \underline{2}, 267-281$.

Holmes, D. S., \& Urie, R. G. Effects of preparing children for psychotherapy. Journal of Consulting and Clinical Psychology, 1975, 43 (3), 311-318.

Hosford, R. E. The cubberley conference and the evolution of observational learning strategies. The Personnel and Guidance Journal, 1980, 58(7), 467-472.

Isenberg, D. P. Automated pre-therapy preparation for individual psychotherapy clients: Relation to client social competence and therapist directiveness (Doctoral dissertation, University of Vermont, 1975). Dissertation Abstracts International, 1975, 35, 5643-5644-B.

Issac, S., \& Michael, W. Handbook in research and evaluation. San Diego, Calif.: Edits, 1971.

Kirk, D. L. A self-instructional program for increasing clients readiness for counseling and psychotherapy: Development and field test (Doctoral dissertation, Florida State University, 1977). Dissertation Abstracts International, $1977,38,2370-\mathrm{B}$.

Krumboltz, J. D. Behavioral goals for counseling. Journal of Counseling Psychology, 1966, 13(2), 153-159.

Krumboltz, J. D. A second look at the revolution in counseling. The Personnel and Guidance Journal, 1980, 58 (7), $463-46 \overline{6}$.

Long, T. J. The effects of pre-training procedures on client behavior during initial counseling interviews (Doctoral dissertation, Arizona State University, 1968). Dissertation Abstracts International, 1968, 16, 1784-A. 
Lukens, H. C. The emission of affective verbal behavior as a function of two modes of experimenter intervention: ${ }^{-} \mathrm{A}$ partial replication and extension (Doctoral dissertation University of Maine, 1969). Dissertation Abstracts International, $1970,31,398-\bar{B}$.

Martin, D. E. Some effects of a pre-therapy procedure on the outcome of out-patient, individual psychotherapy (Doctoral dissertation, University of Tulsa, 1975). Dissertation Abstracts International, 1975, 36, 1444-B.

Maurer, C. G. The effects of a self-instruction program in facilitation and communication skills for elementary school teachers (Doctoral dissertation, University of Florida, 1976). Dissertation Abstracts International, $1977,37,6423-64 \overline{24-A}$.

Merbaum, M., \& Lukens, H. C. Effects of instructions, elicitations, and reinforcements in the manipulation of affective verbal behavior. Journal of Abnormal Psychology, $1968, \underline{73}(4), 376-380$.

Mikulas, w. L. Behavior modification: An overview. New York: Harper \& Row, 1972 .

Mikulas. W. L. Concepts in learning. Philadelphia: W. B. Saunders , 1974 .

Mikulus, W. L. Behavior modification. New York: Harper \& Row, 1978 .

Myrick, R. D. An investigation of client-orientation models in counseling. Doctoral dissertation, Arizona State University, 1968.

Myrick, R. D. Effect of a model on verbal behavior in counseling. Journal of Counseling Psychology, 1969, 16, $185-190$.

Navabinejab, S. Preparation of prospective clients for counseling: A comparison of verbal instructions and modeling as role induction procedures (Doctoral dissertation, University of Nebraska, 1977). Dissertation Abstracts International, 1977, 38, 2670-2671-A.

Orenstein, L. J. Pre-therapy role preparation and attraction induction: An experimental analogue (Doctoral dissertation, Kent State University, 1973). Dissertation Abstracts International, $1974,34,3505-\mathrm{B}$.

Purkey, w. W. Self-concept and school achievement. New Jersey: Prentice-Ilall, 1970. 
Raque, D. W. The effects of video taped pretherapy training program on the behavior of clients during their initial therapy session (Doctoral dissertation, southern Illinois University, 1973). Dissertation Abstracts International, $1974, \underline{34}, 4673-\mathrm{B}$.

Reeves, F. S. The efficacy of verbal pre-therapy information and video-tape modeling as related to client therapeutic outcome and drop-out rate (Doctoral dissertation, Auburn University, 1977). Dissertation Abstracts International, $1978,38,52 \overline{77-B}$.

Reynolds, G. S. A primer of operant conditioning. Glenview, III.: Scott, Forseman \& Company, 1968.

Richardson, G. G. Applied pre-counseling preparation of clients (Doctoral dissertation, Colorado State University, 1976). Dissertation Abstracts International, 1977, 37, $3624-B$.

Rogers, C. R. Client centered therapy. Boston: Houghton, Mifflin, $195 \overline{1}$.

Rogers, C. R. Freedom to learn. Columbus, Ohio: Charles E. Merril1, $196 \overline{9}$.

Sauber, S. R. Approaches to pretherapy training. Journal of Contemporary Psychotherapy, 1974, 6 (2), 190-197.

Scaccuzzo, E. G. What patients want from counseling and psychotherapy. Journal of Clinical Psychology, 1975, 31(3), 471-475.

Scheiderer, E. G. Effects of instructions and modeling in producing self-disclosure in the initial clinical interview. Journal of Consulting and Clinical Psychology, $1977, \underline{45(3), 378-384 .}$

Schmitz, D. R. Facilitating self-disclosure responses in a simulated counseling interview through the use of audiotape modeling, and instruction (Doctoral dissertation, Auburn Universtiy, 1973). Dissertation Abstracts International, $1974,34,6391-63 \overline{92-A}$.

Shannon, G. K. The effects of three modes of preparation for therapy on duration of treatment (Doctoral dissertation, University of Nebraska, 1974). Dissertation Abstracts International, $1975, \underline{36}, 922-\mathrm{B}$.

Shaw, D. E. Wizards, counselors, and other helpers. Unpublished mimeograph, University of Florida, 1980. 
Shery, M. E. The effects of audio-taped psychotherapy pre-training upon client self-exploration. (Doctoral dissertation, University of Southern California, 1975). Dissertation Abstracts International, 1976, 36, 7219-7220-B.

Skinner, B. F. Science and human behavior. New York: Macmillan, 1953.

Skinner, B. F. The technology of teaching. New York: Appleton-Century-Crofts, 1968 .

Slaney, R. B. The effects of precounseling training on the in-counseling behavior of clients (Doctoral dissertation, Ohio State University, 1973). Dissertation Abstracts International, 1974, 34, 4058-B.

Standish, J. T. The use of tape-recordings to train counselors in the use of specific verbal communication skills (Doctoral dissertation, Oregon State University, 1971). Dissertation Abstracts International, 1971, 31, 3887-A.

Thorensen, C. E., Hosford, R. E., \& Krumboltz, J. D. Determining effective models for counseling clients of varying competencies. Journal of Counseling Psychology, $1970, \underline{17}(4), 369-375$.

Tinsley, H. E., \& Harris, D. J. Client expectation for counseling. Journal of Counseling Psychology, 1976, $23(3), 173-17 \overline{7}$.

Urie, R. G. Effects of preparing children for psychotherapy (Doctoral dissertation, University of Kansas, 1974). Dissertation Abstracts International, 1975, 36, 924-B.

VanDerveer, N. J. What is learned in psychotherapy? Cornell Journal of Social Relations, 1974, $9(2), 185-206$.

Whalen, C. Effects of a model and instruction on group verbal behaviors. Journal of Consulting and Clinical Psychology, 1969, 33(5), 509-521.

Wittmer, J., \& Myrick, R. D. Facilitative teaching: Theory and practice. Pacific Palisades, Calif.: Goodyear, 1974.

Wuehler, P. R. A study of the effects of videotaped modeling and counselor/client pre-counseling interaction upon self-disclosure in initial personal assessment feedback counseling interviews (Doctoral dissertation, Brigham Young University, 1975). Dissertation Abstracts International, $1976, \underline{36}, 3635-\mathrm{B}$.

Ziemelis, A. Effects of client preference and expectancy upon the initial interview. Journal of Counseling Psychology, $1974,21(1), 23-30$. 
Daniel Eric Shaw was born May 22, 1951, in New York City, New York. When he was five years old his family moved to North Miami, Florida. After graduating from North Miami Senior High School in June of 1969, he attended Miami Dade Junior College in Miami, Florida, where he earned an Associate of Arts degree in 1971.

He attended the University of Florida in Gainesville, Florida, receiving a Bachelor of Science degree in 1974 and a Master of Education degree in 1975. After teaching psychology at Pensacola Junior College, in 1977 he returned to the University of Florida where he received a Specialist in Education degree in March of 1978. After completing a one-year internship at the Psychological and Vocational Counseling Center at the University of Florida, he accepted a staff position under a federally funded grant for 14 months. Completing his research at the Counseling Center, he received a Doctor of Philosophy degree in June of 1981. He is married to Laurie Jill Samet, a Medical Record Administrator. 
I certify that I have read this study and that in my opinion it conforms to acceptable standards of scholarly presentation and is fully adequate, in scope and quality, as a dissertation for the degreg of Doctor of/Philosophy.

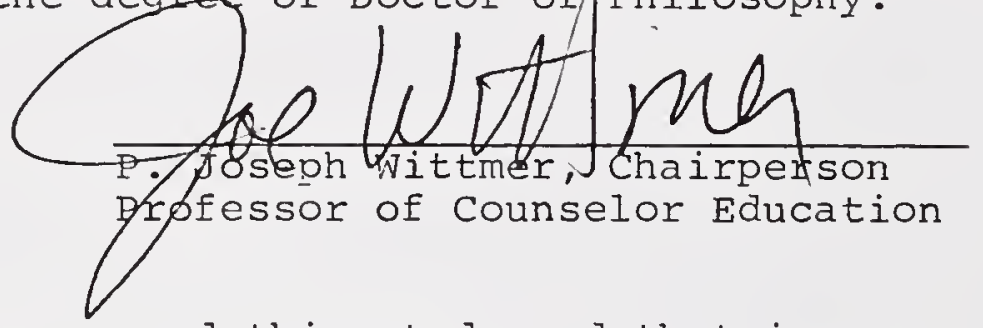

I certify that I have read this study and that in my opinion it conforms to acceptable standards of scholarly presentation and is fully adequate, in scope, and quality, as a dissertation for the degree of Dgctor of philosophy.

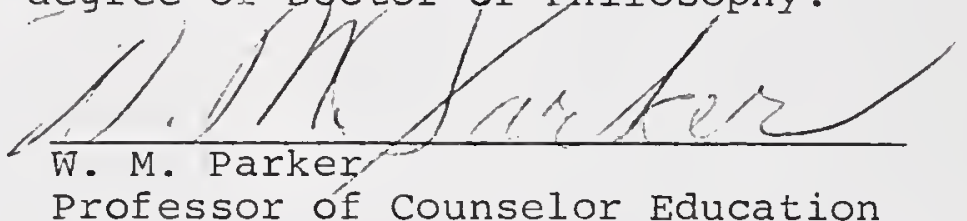

I certify that I have read this study and that in my opinion it conforms to acceptable standards of scholarly presentation and is fully adequate, in scope and quality, as a dissertation for the degree of Doctor of Philosophy.

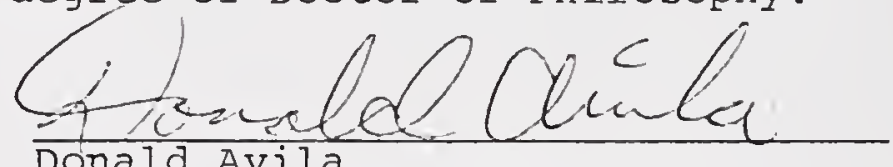
Donald Avila
Professor of Foundations of Education

This dissertation was submitted to the Graduate Faculty of the Department of Counselor Education in the College of Education and to the Graduate Council, and was accepted as partial fulfillment of the requirements for the degree of Doctor of Philosophy

June, 1981 
